IZA DP No. 5796

Inequality and Employment Sensitivities to the Falling Labour Share

Marika Karanassou

Hector Sala

June 2011 


\title{
Inequality and Employment Sensitivities to the Falling Labour Share
}

\author{
Marika Karanassou \\ Queen Mary, University of London \\ and IZA \\ Hector Sala \\ Universitat Autònoma de Barcelona \\ and IZA
}
Discussion Paper No. 5796
June 2011

IZA

P.O. Box 7240

53072 Bonn

Germany

Phone: +49-228-3894-0

Fax: +49-228-3894-180

E-mail: iza@iza.org

\begin{abstract}
Any opinions expressed here are those of the author(s) and not those of IZA. Research published in this series may include views on policy, but the institute itself takes no institutional policy positions.

The Institute for the Study of Labor (IZA) in Bonn is a local and virtual international research center and a place of communication between science, politics and business. IZA is an independent nonprofit organization supported by Deutsche Post Foundation. The center is associated with the University of Bonn and offers a stimulating research environment through its international network, workshops and conferences, data service, project support, research visits and doctoral program. IZA engages in (i) original and internationally competitive research in all fields of labor economics, (ii) development of policy concepts, and (iii) dissemination of research results and concepts to the interested public.
\end{abstract}

IZA Discussion Papers often represent preliminary work and are circulated to encourage discussion. Citation of such a paper should account for its provisional character. A revised version may be available directly from the author. 
IZA Discussion Paper No. 5796

June 2011

\section{ABSTRACT \\ Inequality and Employment Sensitivities to the Falling Labour Share*}

This paper aims at identifying the labour share (wage-productivity gap) as a major factor in the evolution of inequality and employment. To this end, we use annual data for the US, UK and Sweden over the past forty years and estimate country-specific systems of labour demand and Gini coefficient equations. Further to the statistical significance of our models, we validate their economic significance through counterfactual simulations. In particular, we evaluate the contributions of the labour share to the trajectories of inequality and employment during specific time intervals in the post-1990 years. We find that during the nineties the cost of a one percent increase in employment was in the range of $0.7 \%-0.9 \%$ higher inequality in all three countries. However, in the 2000s, whereas the inequality-employment sensitivity ratio slightly fell in the US, it exceeded unity in the countries on the other side of the Atlantic. It obtained its highest value in the UK, where a $1 \%$ growth in employment was achieved at the expense of $1.3 \%$ worsening in income inequality. In the light of the significant influence of the time-varying labour share on the inequality and employment time paths documented in our sample, the evolution of the wage-productivity gap deserves the attention of policy makers.

JEL Classification: D30, E25, E24

Keywords: income inequality, labour income share, employment

Corresponding author:

Hector Sala

Department d'Economia Aplicada

Universitat Autònoma de Barcelona

Edifici B

08193 Bellaterra

Spain

E-mail: hector.sala@uab.es

\footnotetext{
* We are grateful to the Spanish Ministry of Science and Innovation for financial support through grant ECO2009-07636. We have benefited from discussions with John Hatgioannides.
} 


\section{Introduction}

This work dwells on the influence of the labour share (wage-productivity gap) on two vital macro-labour outcomes: employment and income inequality. Since the late 1960s, the relationship between macroeconomic activity and inequality has been widely examined in the literature. In a seminal paper, Schultz $(1969$, p.83) states that "the secular growth of labour's share, which tends to be more equally distributed among persons than that of profits or property, has undoubtedly worked to reduce over-all inequality of personal income". Since the 1970s, though, the harsh reality is that the labour share has mainly evolved along a downward path. So we are due to ask what are the repercussions of the fall in the labour share. Our framework of analysis identifies the wage-productivity gap as an important channel fueling income inequality and supporting employment.

Studies that approach the inequality/macro-activity nexus from a time series perspective have mainly followed two avenues: either a measure of inequality (such as the Gini coefficient or the quintile income shares) acts as the dependent variable in a macrolabour econometric model, or a parametric distribution is fitted to the observed income distribution and its estimated parameters are, in turn, regressed on a set of macro-labour variables. $^{1}$ These analyses assert that (un)employment is a major channel via which macroeconomic fluctuations affect the size distribution of personal income.

From the plethora of papers which directly estimate the impact of unemployment on the summary statistic of income inequality, i.e. the Gini coefficient, our point of departure hints to justifiable methodological and political economy questions. First, can the positive correlation between the Gini coefficient and unemployment offer a comprehensive explanation of inequality or is it merely a statistical regularity? Second, which of the determinants of inequality can also produce a positive outcome (e.g. a rise in employment) that effectively diverts the attention of developed democratic societies from the issue of increasing inequality by "sweetening" its impact?

This paper contributes to the income distribution literature by postulating that the labour share (wage-productivity gap) is a major driving force of the evolution of inequality and employment. In this respect, our aim is to examine how the labour share channel irrigates the inequality-(un)employment landscape.

In what follows, we first produce evidence that over the past four decades a falling

\footnotetext{
${ }^{1}$ The majority of the studies examining the influence of macroeconomic conditions on the size distribution of personal income have followed the inequality regression avenue, strarting with Schultz (1969) who used a Gini regression, and Blinder and Esaki (1978) who used income shares regressions. The income shares approach addresses the issue of whether unemployment (and other variables) have regressive or progressive effects on the size distributon of income. Nolan (1988), Bjorklund (1991), and Mocan (1999) are among the studies that use income shares regressions, while Cysne (2009), and Checchi and García-Peñalosa (2010) are among those ones estimating a Gini regression. Fewer studies have followed the parametric distribution avenue which started with Metcalf (1969), Thurow (1970), and continued recently with Jäntti and Jenkins (2010).
} 
labour share has been accompanied by a worsening income inequality - the latter has been particularly emphasized by a variety of authors in both the academia and the press. These developments have taken place in a globalised environment featuring the interplay of technological progress, product/labour market policies, and financialisation. ${ }^{2}$ We then estimate country-specific models of employment and income inequality equations for the US, UK and Sweden. We show that the widening wage-productivity gap (i.e. wages lagging further behind productivity) has, on one hand, significantly contributed to the rise in inequality (measured by the Gini coefficient), and, on the other, boosted employment. These results not only are in line with the observation by Krugman (1994, p.23) that "... the United States has achieved low unemployment by a sort of devil's bargain, whose price is soaring inequality... ", but they also show that this is the case across the Atlantic.

It is generally believed that a shift of demand away from unskilled labour towards skilled labour has led to both increased income inequality in the US and high unemployment in Europe. Atkinson (2001) dubbed this view the 'Transatlantic Consensus', albeit arguing that this consensus is open to question (see also Singh, 2001). Our results are in stark contrast to the 'Transatlantic Consensus', since, like the US, both European countries in our sample, the "egalitarian" Sweden and "non-egalitarian" UK, are found to support their employment levels by a devil's bargain.

Having established the statistical significance of our empirical framework of analysis, we investigate its economic significance and measure the dynamic contributions of the falling labour share to the evolution of inequality and employment. We find that during the 1990s all three countries experienced inelastic inequality-employment sensitivity ratios in the range of 0.7 to 0.9 , i.e. a one percent increase in employment was associated with less than $1 \%$ higher inequality. However, in the 2000s, whereas the inequality-employment ratio slightly fell in the US, it exceeded unity in the countries on the other side of the Atlantic. It obtained its highest value in the UK, where a $1 \%$ growth in employment was achieved at the expense of $1.3 \%$ worsening in income inequality. This increase was due to the dramatic rise of the inequality-labour share sensitivity, which almost doubled from the nineties to the noughties, implying that the same percentage fall in the labour share in the 1990s led to twice as much the rise in inequality in the 2000s.

Interpreting these sensitivity ratios as 'tradeoffs' is debatable, since a tradeoff requires the identification of some policy instrument(s) that could directly affect its balance. The inflation-unemployment tradeoff is one such example. Regressing inflation on unemployment is a direct way to measure the tradeoff between the two phenomena, i.e. evaluate the slope of the Phillips curve. This has profound policy implications, since monetary policy is a major causal factor of the inflation-unemployment tradeoff. In contrast, as it is

\footnotetext{
${ }^{2}$ The recent term 'financialisation' refers to the engagement of non-financial businesses in financial markets (Stockhammer, 2004; Milberg and Winkler, 2010).
} 
rather unclear how to balance an inequality-(un)employment tradeoff, ${ }^{3}$ the value added of regressing the Gini coefficient on the unemployment rate (and finding that unemployment increases inequality) is questionable.

The rest of the paper is structured as follows. Section 2 discusses the evolution of inequality and the labour share from the mid 1960s to 2008. Section 3 analyses the anatomy of the labour share channel and outlines our employment and Gini coefficient relationships. Section 4 gives the estimation results. Section 5 evaluates the contributions of the labour share to the inequality/employment trajectories during the 1990s and 2000s. Section 6 concludes our thoughts.

\section{A Bird's Eye View of Inequality and the Labour Share}

\subsection{Inequality Coming Back with Vengeance}

The increase in inequality has been documented by many authors in both the academia and the press. Here we present some key developments in the inequality landscape that point to a worrying regression of inequality after 1980 to levels similar to those of the pre-WWII era.

In their investigation of wealth and income inequality in the US in 1982-2000, Wolff and Zacharias (2006) evidence a gain of 9.5 percentage points in the income share of the top decile (from $33.4 \%$ to $42.9 \%$ ). The inequality gap is further magnified when we look at the very high end of the distributional spectrum: the share of the top percentile increased from $9.9 \%$ to a staggering $17.4 \%$. These results are in line with Piketty and Saez (2006) who find that during the 20th century the top percentile has fluctuated from around $18 \%$ before WWI, to only around $8 \%$ in the 1960s and 1970s, and back to around $17 \%$ by 2000. In a brief overview of trends in income inequality, Mankiw (2010) notes that since the mid-1970s the share of total income of the top $0.01 \%$ (i.e. those with annual income of more than $\$ 11$ million) has increased about sixfold.

According to the high pay commission, set up in November 2010 to scrutinise the rising pay of those at the top of the public and private sectors, the share of the top $0.1 \%$ of UK earners is $5 \%$ of national income. The commission further claims that "Wage disparity between the UK's top earners and the rest of the working population will soon return to the levels of the Victorian era..."4

In the Financial Times ('Stuck in the Middle', 29/10/2008) we read that "Between 2000 and 2006 the US economy expanded by 18 per cent, whereas real income for the

\footnotetext{
${ }^{3}$ The inequality-unemployment tradeoff is discussed in Hellier and Chusseau (2010), among others.

4'Pay gap widening to Victorian levels', The Guardian, 16 May 2011, Graham Snowdon.
} 
median working class dropped by 1.1 per cent ... Meanwhile, the top tenth saw an improvement of 32 per cent in their incomes, the top 1 per cent a rise of 203 per cent the top 0.1 per cent a staggering gain of 425 per cent." Wolff and Zacharias (2006, p. 5) note that in 2004 , the median net worth of the individuals in the Forbes 400 list was $\$ 1.5$ billion "as compared to the median net worth of $\$ 93,000$ for all other households."

As the increase in the share of the top percentile has been accompanied by the exceptional growth in top executives' pay relative to the salaries of employees, the issue of whether the so called "working rich"5 have replaced top capital owners (the "rentiers") at the top of the economic ladder is open to debate. For example, Wolff and Zacharias (2006) do not support this issue, whereas Piketty and Saez (2006) argue in its favour. Economists of the Washington consensus have labelled such a wealth redistribution 'median wage stagnation' and are stunned about the complexity of the problem and its causes. Others dub it the 'silent recession' (Financial Times, 'Stuck in the Middle', 29/10/2008).

We should note that, in a globalised world, the rising inequality is not confined to the US and UK economies. According to Llense (2010, p. 1) "the sharp increase in globalization and the last privatization wave have promoted the shaping of a market for executives in France." In Japan, traditionally considered as an egalitarian society, inequality has been rising since the eighties. Moriguchi (2010, p. 7) links this increase to "a faster growth of wage income at the high end of the distribution". Furthermore, Bourguignon and Morrisson (2002) examine inequality among world citizens using data from 1820 to 1992 and find that, while the income share of the top decile was relatively stable about 50 percent throughout the 1950s to the 1970s, it started increasing in 1980, reaching its highest value of 53.4 percent in 1992 (ibid, Table 1, p. 731-732.)

\subsection{Defining the Measures}

Our work adopts the Gini coefficient (Gini ratio, or relative income) as the summary measure of income inequality in a population. ${ }^{6}$ The most common interpretation of the Gini statistic is the area between the curve in a Lorenz diagram and the diagonal $\left(45^{\circ}\right)$ line as a ratio of the area below the diagonal. (The Lorenz curve plots the cumulative population shares, from the poorest to the richest, against their cumulative income shares.) The values of the Gini coefficient are in the $[0,1]$ range, a higher coefficient is associated

\footnotetext{
5 "Forbes popularised this term. However, the magazine used it in the sense that the wealthiest Americans hold jobs rather than in the sense that the wealthiest depend mainly on labour income as their chief source of income." (Wolff and Zacharias, 2006, p. 12).

${ }^{6}$ The Gini coefficient is most easily calculated from unordered size income $(x)$ data as the "relative mean difference', i.e., the mean of the difference between every possible pair of individuals, divided by the mean size $\mu$,

$$
\text { Gini }=\frac{\sum_{i=1}^{n} \sum_{i=1}^{n}\left|x_{i}-x_{j}\right|}{2 n^{2} \mu} .
$$

(http://www.wolframalpha.com/input/?i=gini+coefficient)
} 
with higher income inequality: zero is the case of perfect equality with each member of the population receiving exactly the same income, whereas one is the case of perfect inequality with single member receiving all the income and the rest receiving none.

However, using the above standard definition, a specific Gini coefficient value falls short of immediate comprehension. Shorrocks (2005) offers an intuitive and easy to understand interpretation of the value of the Gini coefficient as a division of a "pie" into two unequal shares. For example, he explains that a Gini value of 0.40 is obtained from the division of an aggregate economic pie worth $\$ 1$ into 90c and 10c. Presenting inequality as "a 2-way division of a pie in which one person gets 9 times the other is a powerful way of capturing the extent of income differences." Since the "fair" share in a 2-way division is 0.5 , the Gini value of 0.40 represents the excess share of the richest person (Gini $=0.90-0.50$ ). Put differently, the Gini value can be comprehended as the excess share of the rich in a 2-class society. In a 10 person society, the Gini value of 0.40 can be pictured as the division of a $\$ 1$ pie between one person receiving 0.50 of the pie and nine people each getting $(0.50 / 9) \approx 0.05$. In other words, the share of the richest person is the fair share 0.1 plus the Gini value.

Regarding the labour income share, i.e. the average real wage as a ratio of productivity, it is important to recognise that it is equivalent to the wage-productivity gap: ${ }^{7}$

$$
\text { labour share } \equiv \frac{\text { wages }}{\text { GDP }}=\frac{\text { wages/employees }}{\text { GDP/employees }}=\frac{\text { avg. wage }}{\text { productivity }} \equiv \text { wage gap. }
$$

If, say, a $10 \%$ productivity gain is accompanied by a $10 \%$ growth in the average real wage, then the wage gap is zero. However, the lower the wage growth, the more wages trail productivity gains and thus the higher is the wage gap.

The Economist speaks volumes when reporting that, since 2000, "The fruits of productivity gains have been skewed towards the highest earners, and towards companies, whose profits have reached record levels as a share of GDP" (Special report: Inequality in America, 2006, June 17). Below we present the time series of the inequality and labour share measures.

\subsection{A Tale of the Time Paths}

Figure 1 plots the Gini coefficients for the US, UK and Sweden. This graphic evidence suggests that, since the late 1970s, income inequality has evolved in terms of upward 'trends' rather than 'episodes' of falling/increasing inequality. As inequality has been growing in all three countries, the US has been experiencing the highest levels, followed closely by the UK and with Sweden approaching rather fast.

\footnotetext{
${ }^{7}$ We should also note the intricate association of the labour share to the (real) unit labour cost; the latter is defined as the average (real) cost of labour per unit of real output.
} 
Figure 1. Income inequality.

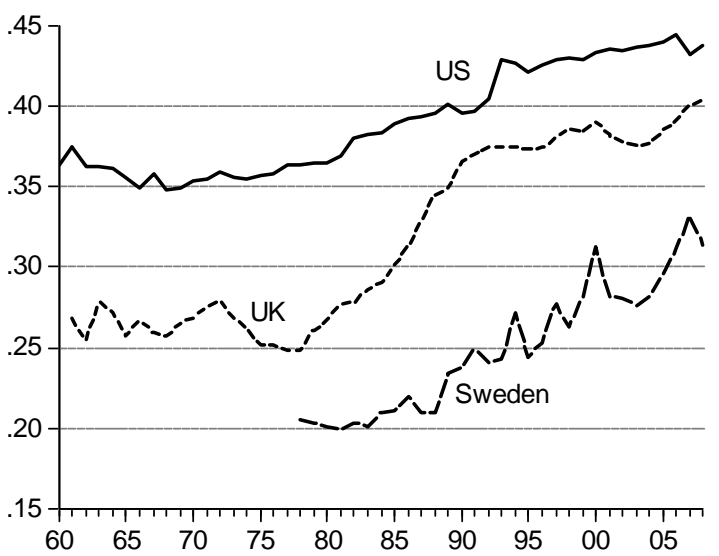

Characteristically, in the mid/late 1970s, the Gini coefficient was close to 0.35 in the US, 0.25 in the UK, and 0.20 in Sweden. By 2008 the statistic of inequality reached the value of 0.44 in the US, 0.40 in the UK, and 0.32 in Sweden. It is important to bear in mind that, in the US and the UK, whereas the macroeconomic environment of the stagflating 1970s featured rapidly rising unemployment rates and modest levels of income inequality, the roaring nineties were characterised by relatively low unemployment rates and ever increasing inequality.

Note, however, that although the levels of inequality witnessed in the two European countries have been lower than those in the US, they have been growing at much higher rates over the past 30 years: inequality increased by $60 \%$ in the UK and $55 \%$ in Sweden, compared to $15 \%$ in the US. Regarding the UK, Atkinson (1997, p.301) noted that the country "stands out for the sharpness of the rise in recorded income inequality in the 1980s... The apparent fall in the redistributive impact of transfers and direct taxes since the mid-1980s is circumstantial evidence that policy changes have contributed to the rise in income inequality" (ibid, p.306). Using both National Accounts annual data and micro-data from the 1977 Family Expenditure Survey, Nolan (1987) showed that after the late 1970s the share of top income groups had risen in a way that was unprecedented since the late 1940s, and this was mostly at the expense of the middle of the distribution. Regarding Sweden, it is worth pointing out that the breakdown of centralized bargaining and the subsequent earnings compression of the mid-1980s signalled the upward trend in inequality over the past thirty years.

Regarding the labour share, although widely assumed in the literature, the theoretical property of its constancy is strongly refuted by reality. The plots in Figure 2 evidence the falling labour share in the US since the 1960s, and in the UK and Sweden since the mid/late 1970s (as explained in Section 4, the labour share is adjusted for self-employment income). 
Figure 2. The labour share.

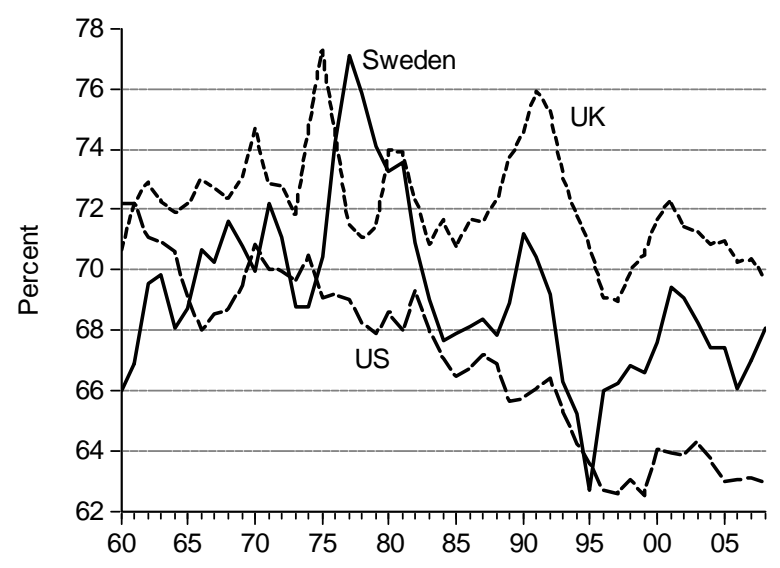

It is worth noting that while the US labour share attained its highest value $(72 \%)$ in 1961, the European labour shares recorded their top value of $77 \%$ in 1975 (UK) and 1977 (Sweden). Clearly, whereas the labour share in the US has been evolving smoothly around a downward trend, the two labour shares across the Atlantic have been exhibiting profound ups and downs that decelerated their falling trajectories since the mid 1970s.

The disparity between the highest value of the labour share and its end of sample (2008) value is 9 percentage points, pp, in the US (72\%-63\%), 7 pp in the UK $(77 \%-70 \%)$, and 9 pp in Sweden $(77 \%-68 \%)$. We should also point out that both European countries experienced an accelerated reduction in their labour shares during the nineties, i.e. their labour shares were falling by more than one percentage point per year. More precisely, the labour share fall in the UK was 7 pp during 1991-97 (slope $=-1.2$ ) and in Sweden 8 pp during 1990-95 (slope $=-1.6) .^{8}$

Recent literature has identified three interrelated factors as responsible for the decline in the labour shares: globalisation, technological progress, and product and labour market policies. The mechanisms through which compensation and job creation grow at a rate slower than economic growth are, among others, trade shares and terms-of-trade prices, foreign direct investment, offshoring, migration flows, and financial openness (Guscina, 2006; IMF, 2007). In addition, technological progress tends to increase returns to capital and, thus, the capital income share. In turn, in seeking to maintain competitiveness, the product and labour market policies typically undertaken have tended to weaken the bargaining position of labour vis-à-vis the firm (Bentolila and Saint-Paul, 2003; Ellis and Smith, 2007; Bental and Demouguin, 2010).

Viewing the falling labour shares as the ratification of rising profits, it is reasonable to argue that the inequality-employment sensitivity ratio (i.e the percentage increase in inequality associated with one percent increase in employment) depends, among other

\footnotetext{
${ }^{8}$ A slope $<-1$ means that the reduction rate exceeded 1 pp per year over a given period.
} 
things, on how profits are being spent. Milberg and Winkler (2010) argue that when the non-financial corporate sector channels part of the rise in profits to higher dividend payments and share buybacks, a leakage is created in the profits-investment-employment system. A partial, instead of full, recycling of the rise in profits into investment is the result of financialisation which reflects the tilt in the focus of non-financial sector corporate strategies towards short-term maximisation of shareholder value at the expense of longterm growth.

The thesis of this paper is that the falling labour share aggravates inequality and contributes positively to employment. It is worth pointing out that our results contradict the Neoclassical paradigm (with its representative agent model) that dismissed the link between income distribution and macroeconomic activity. In addition, since being employed (rather than unemployed) makes it easier to tolerate increasing inequality, finding that the labour share channel links inequality and employment is alarming if income inequality has adverse effects on economic growth. Although the inequality/growth nexus is beyond the scope of this paper, we should note that, unlike the Classical hypothesis, the modern viewpoint of the relationship between inequality and economic development argues that a more equal distribution of income promotes economic growth (Galor and Moav, 2004; Galor, 2011).

\section{Anatomy of the Labour Share Channel}

Given that the labour share represents the part of the economic pie that goes to labour, rather than profits, distributional issues at the core of this concept remain intact whether we call it labour income share (wage share) or wage-productivity gap (real unit labour cost). As the previous section highlighted, the downward sloping trajectory of the labour share has been accompanied by worsening income inequality. This was pictured in Figures 1, 2 and is also shown in Figure 3 from a country-specific perspective.

Figure 3. Income inequality vs. the labour share.

a.us

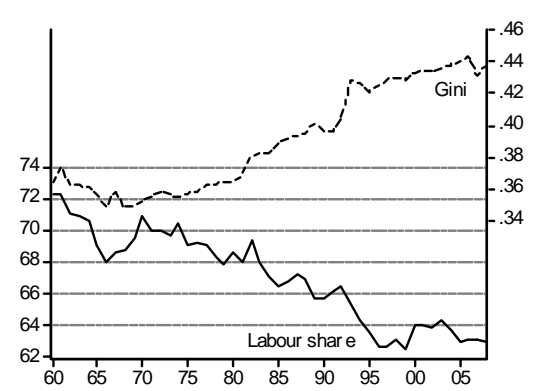

b. UK

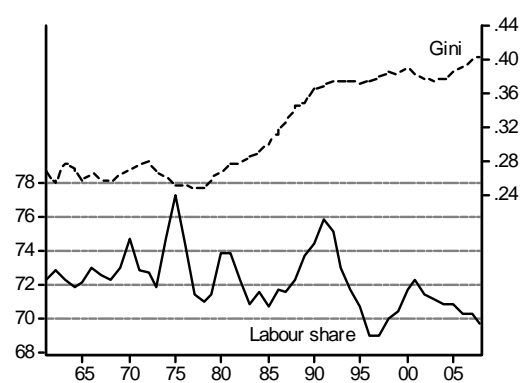

c. Sweden

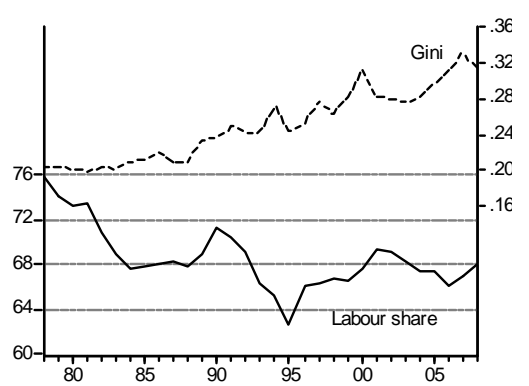

We view globalisation as a phenomenon that encapsulates (among other things) the interactive dynamics of technological progress and product/labour market policies in a 
world of growing inequality. From the statistics and selected literature in Section 2, it is apparent that globalisation leads to higher employment, whilst it is accompanied by a more unequal income distribution. Karanassou and Sala (2010) argued that the labour share is a driving force of employment; in this paper we demonstrate that the wageproductivity gap is also an important factor prompting inequality. Acknowledging that the boost in employment is one side of the globalisation coin, and its flip side is the worsening of inequality, the labour share can be seen as the footprint of the globalised employment/income inequality mix (Figure 4$){ }^{9}$

Figure 4. Anatomy of the labour share channel.

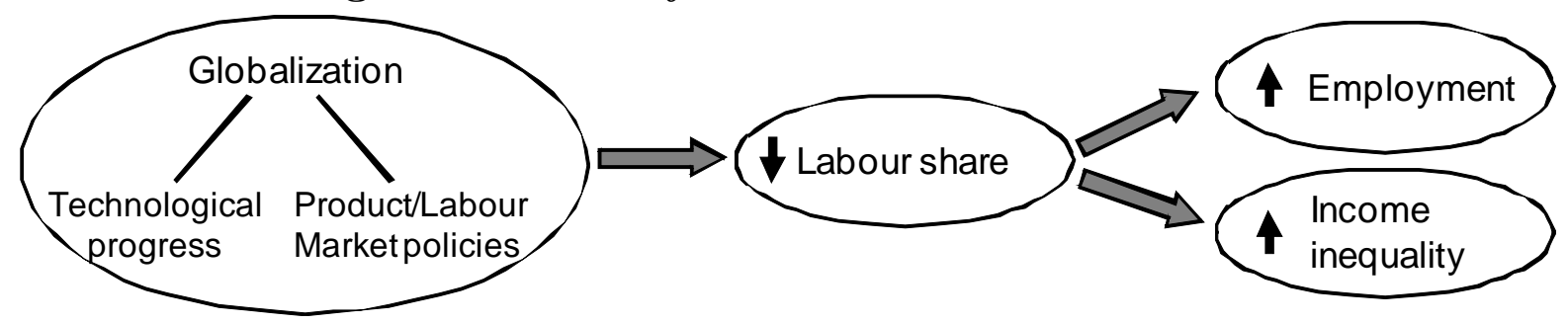

In particular, in Karanassou and Sala (2010) we argued that the neoclassical picture of productivity gains being fully translated into wage rises can only prevail in the absence of dynamics and growth. The incumbent view that the labour income share is neutral to labour demand was thus challenged. Whilst maintaining the assumption of a one-to-one relationship between real wages and productivity in the long run, we demonstrated that productivity growth affects the labour share in the long run due to frictional growth, a phenomenon generated by the interplay of wage dynamics and productivity growth. In effect, we showed that the wage-productivity gap instead of being absent in the long run, transforms to frictional growth. Furthermore, our analytical exposition was validated empirically: using a sample of seven OECD countries over the 1960-2008 period we found that the time-varying labour share is a major determinant of employment.

It should be noted, however, that the link between a falling labour share and the employment boost shies away from the terms of employment. These are associated with the existence of a national health system, state pension, benefits system, the time it takes to re-establish benefits, strings attached to receive benefits, minimum wage, and lack of progression. We believe that the deterioration of the latter is taken into account when we evaluate the link between the falling labour share and rising inequality.

The thrust of this work is to address the sibling pathways of the globalised employment/income inequality fusion by investigating how the falling labour share (or, equivalently, the widening wage-productivity gap) influenced the employment trajectory and

\footnotetext{
${ }^{9}$ Note that financialisation represents a leakage in the labour share-employment channel of Figure 4. That is, when profits are not fully recycled into investment, the employment support of falling labour shares is weaker than otherwise.
} 
solicited the increasing inequality in the US, UK and Sweden over the past four decades. To this end, we use a system comprising labour demand and inequality equations, and show that a decrease in the labour share creates more inequality and leads to higher employment (or lower unemployment). ${ }^{10}$ Our findings not only are in line with the point made in Krugman (1994, p.23) that "... the United States has achieved low unemployment by a sort of devil's bargain, whose price is soaring inequality... ", but they also show that this is the case on the other side of the Atlantic.

It can be argued that these findings indicate that the widening wage-productivity gap has been encouraged by a 'carrot and stick' approach - employment being the reward, insecurity of loosing the job (due to a deterioration in labour conditions) being the threat. Nevertheless, a debate on the terms of employment and their link to labour demand is beyond the scope of this paper.

Next we outline our employment and Gini coefficient relationships.

\section{Employment vis-à-vis the Wage Gap}

As in Karanassou and Sala (2010), we consider a standard log-linear labour demand equation:

$$
n_{t}=\phi_{0}+\phi_{1} n_{t-1}-\phi_{2} w_{t}+\phi_{3} p r_{t}+\text { "other" }+\varepsilon_{1 t},
$$

where $n_{t}, w_{t}, p r_{t}$ denote employment, real wages, labour productivity (all in logs), $\varepsilon_{1 t}$ is a strict white noise error term, and the $\phi$ 's are positive parameters; the autoregressive parameter $\phi_{1}<1$ captures employment adjustment costs, such as costs of hiring and firing, search costs, and training costs. Note that productivity $(p r)$ can be thought of as capturing technological change (this is common in the literature - see, for example, Blanchard, 2006, p. 17). The "other" explanatory variables refer to real interest rates or real balances, competitiveness, and private consumption (see Section 4). We should also point out that the log difference between real wage and productivity is a key element in the Hatton (2007) unemployment rate equation (2), which can also be seen as a dynamic labour demand equation (p. 480). Finally, equation (2) can be reparameterised as

$$
\begin{aligned}
n_{t} & =\phi_{0}+\phi_{1} n_{t-1}-\phi_{2}\left(w_{t}-p r_{t}\right)+\left(\phi_{3}-\phi_{2}\right) p r_{t}+\text { "other" }+\varepsilon_{1 t} \\
& =\phi_{0}+\phi_{1} n_{t-1}-\phi_{2} l s_{t}+\left(\phi_{3}-\phi_{2}\right) p r_{t}+\text { "other" }+\varepsilon_{1 t},
\end{aligned}
$$

where $l s_{t}$ stands for the labour share (wage-productivity gap), and higher order lags are ignored for expositional simplicity.

\footnotetext{
${ }^{10}$ It can be shown that when a labour supply equation is added to the system, the unemployment rate is associated negatively to the labour share. To conserve space, the results are available upon request.
} 


\section{Gini Coefficient vis-à-vis the Wage Gap}

Along a similar line to equation (3), we postulate an autoregressive distributed lag model for income inequality:

$$
\operatorname{gini}_{t}=\beta_{0}+\beta_{1} \text { gini }_{t-1}-\beta_{2}\left(w_{t}-p r_{t}\right)+\left(\beta_{3}-\beta_{2}\right) p r_{t}+\beta_{4} f p_{t}+\text { "other" }+\varepsilon_{2 t},
$$

where gini $_{t}$ is the Gini coefficient (in $\operatorname{logs}$ ), $f p_{t}$ denotes financial corporations profits, and the $\beta$ 's are positive parameters with $\beta_{1}<1$. The "other" explanatory variables may include taxes, competitiveness, union density, and benefits. Higher order lags are ignored for expositional simplicity, and $\varepsilon_{2 t}$ is a strict white noise error term. Although the above specification is along the lines of the reduced form inequality equation in Checci and García-Peñalosa (2010), it does not include unemployment as an explanatory variable for reasons we explain below.

It has been argued that higher corporate profits as a share of national income lead not only to higher investment but to the 'financialisation' of the industry as well, i.e. the engagement of non-financial businesses in financial markets (Stockhammer, 2004; Milberg and Schöller, 2008; Milberg and Winkler, 2010, among others). Recognising the link between financialisation and financial profits (e.g. via fees), the finding that the profits of the financial sector have a positive impact on the Gini coefficient implies that financialisation has a "direct" adverse effect on inequality. (The indirect effects of financialisation on inequality are via the labour share.)

The Gini coefficient captures inequality by measuring the allocation of income in (real) monetary terms to the various groups of agents. Therefore, wages, benefits, rewards to capital or labour, and institutions that facilitate such rewards are legitimate candidate variables on the right-hand-side of a Gini regression, while adding unemployment as an explanatory variable risks blurring the picture of analysis. For example, the negative and insignificant unemployment coefficient in the Gini equation of Checchi and GarciaPeñalosa (2010) using OLS and IV (Table 4, p. 428) becomes positive and significant with 3SLS (Table 5, p. 431). As it is hard to justify such a u-turn of the estimates on the grounds of endogeneity and cross-equation correlation alone, we believe that the authors' finding "that these simulations contradict the perception that higher inequality is associated with lower unemployment" (p. 435) drops in face value.

Nevertheless, the belief that higher unemployment increases inequality is reasonable, since unemployment hits hardest those with low earnings capacity, even when they have a job (e.g. Björklund, 1991). We should point out that, for at least the past forty years, it has been recognised that unemployment has distributional effects (e.g. Tobin, 1972). The inequality/unemployment issue can be addressed by examining the relationship between the various income classes and the existence of unemployment. Using US data, Blinder 
and Esaki (1978) introduced the approach of regressing the share of the $i^{\text {th }}$ quintile in the distribution of income on the overall unemployment rate, and found that a rise in unemployment causes the share of the two lowest two quintiles to decrease by the same amount that the share of the highest quintile increases. ${ }^{11}$

\section{Empirical Analysis}

\subsection{Data and Variable Definitions}

Table 2 presents the variables in the selected specifications of the labour demand and inequality equations. ${ }^{12}$

Table 2. Definitions of variables.

\begin{tabular}{ll|ll}
\hline \hline & & & \\
$l s$ & labour share $(=w-p r)$ & $u d$ & trade union density (\%) \\
$w$ & real compensation per employee & $\tau^{d}$ & direct taxes (\% of GDP) \\
$p r$ & labour productivity $(=y-n)$ & $\tau^{i}$ & indirect taxes (\% of GDP) \\
$y$ & GDP at market prices & $r b$ & real balances \\
$n$ & employment & $r$ & real interest rates (\%) \\
$g i n i$ & gini coefficient & comp & competitiveness \\
$f p$ & $\frac{\text { profits of financial corporations }}{\text { total profits of corporations }}$ & $c$ & private consumption \\
$g s$ & $\frac{\text { gross operating surplus of financial corporations }}{\text { total gross operating surplus }}$ & & (\% of GDP) \\
$n s$ & $\frac{\text { net operating surplus of financial corporations }}{\text { total net operating surplus }}$ & $d^{00}$ & dummy (value 1 in 2000) \\
\hline \hline
\end{tabular}

Note: $\quad$ Variables are in logs unless otherwise indicated.

Sources: OECD (Economic Outlook, Employment and Labour Market Statistics), US

Census Bureau, US Bureau of Economic Analysis, UK Office for National

Statistics, Institute for Fiscal Studies (London, UK), Statistics Sweden

As in Karanassou and Sala (2010), we follow the European Comission methodology in their Ameco database and compute the adjusted labour share as

$L S=\frac{\text { total compensation/dependent employment }}{\text { GDP at factor costs/total employment }}=\frac{\text { total compensation }}{\text { GDP at factor costs }} \frac{\text { total employment }}{\text { dependent employment }}$

In this way, total labour compensation includes both dependent and self-employment compensation, and GDP excludes taxes and subsidies, which are not a component of

\footnotetext{
${ }^{11}$ Clearly, the sensitivities of each quintile to the unemployment rate satisfy the cross-equation restriction of summing up to unity. The study of Blinder and Esaki was followed, among others, by Nolan (1988), Bjorklund (1991), and Mocan (1999).

${ }^{12}$ Although we have worked with extended datasets for the three economies considered, here we only report the variables entering the selected estimated equations.
} 
generated income and need to be excluded from the calculation of the labour income share. Once the labour share is computed, we retrieve the average wage per employee (including self-employment) as $W=\frac{L S * Y}{N}$, where $N$ is total employment and $Y$ is the standard measure of GDP at market prices. Note that $w, n, y$, and $l s$ (defined in Table 2) are the log counterparts of $W, N, Y$ and $L S$. It follows that the labour share, $l s=w-p r$, can also be interpreted as the wage-productivity gap. Information on these variables is obtained from the OECD Economic Outlook.

Regarding income inequality, time series data for the US are supplied by the US Census Bureau and correspond to gini ratios for families. For the UK, the source is the Institute for Fiscal Studies (see Joyce et al., 2010). Incomes are net of direct taxes and measured at the household level. For Sweden, data are supplied by Statistics Sweden and consist on after-tax gini coefficients for households.

We capture the role played by financial profits in shaping the upward trend in income inequality by using different variables in each country, depending on data availability. Given that the US Census Bureau supplies data for both corporate financial and nonfinancial profits, we construct the variable $f p$ as the ratio of financial profits over total profits. For the UK, the variable used as a proxy of financial profits is the ratio of financial corporations gross operating surplus over total gross operating surplus, $g s$, while in Sweden the same ratio was constructed in terms of net operating surplus, $n s .{ }^{13}$

The other variables used are union density $(u d)$; direct and indirect taxes $\left(\tau^{d}, \tau^{i}\right)$ as a percentage of GDP; real interest rates $(r)$, defined as the difference between the nominal interest rate and the inflation rate (i.e. the rate of change in the GDP deflator); real money balances $(r b)$, defined as a broad measure of money supply over the GDP deflator; a standard measure of competitiveness (comp), defined as the ratio of import prices over the GDP deflator (in logs); and private household consumption (c) as percentage of GDP. Information on these variables is taken from the OECD.

\subsection{Estimation Results}

Our econometric methodology is based on the autoregressive distributed lag (ARDL) approach (or bounds testing approach) which has been shown to yield consistent shortand long-run estimates and has desirable properties even in the face of unit roots (see Pesaran, 1997; Pesaran and Shin, 1999; Pesaran, Shin and Smith, 2001). Since an ARDL equation can be reparameterised in error-correction form and its long-run solution can

\footnotetext{
${ }^{13}$ US data on profits are net since they include inventory valuation and capital consumption adjustments. For the UK, the Office for National Statistics does not supply the net operating surplus. While both gross and net surpluses are available in Sweden, we don't find any significant differences in the Gini equation estimates when using either of the two. However, the limitation in Sweden is that these variables are available from 1993 onwards. This implies that $n s$ enters the equation as a dummy taking value 0 from 1978 to 1992 , which is equivalent to say that in the earlier part of the sample this ratio had no role in shaping inequality in Sweden.
} 
be interpreted as the cointegrating vector of its variables, the ARDL procedure can be viewed as an alternative to the standard integration/cointegration techniques.

The empirical labour demand and income inequality equations are augmented versions of the stylised model (3)-(4). Our selected specifications attempt to optimise the fit for each country, and their dynamics are determined by the optimal lag-length algorithm of the Schwarz information criterion. All equations are dynamically stable and pass the standard diagnostic tests (for linearity, no serial correlation, homoskedasticity, normality, and structural stability) at conventional significance levels. As shown in Figures 5a, 6a, and $7 \mathrm{a}$ the fitted trajectories of employment and Gini coefficients track closely the actual ones. To take into account the potential endogeneity and cross equation correlation, we estimate the employment/inequality model with 3 SLS. ${ }^{14}$ Table 3 presents the estimated systems of equations for the US, UK, and Sweden. We should note that although the labour demand and Gini regressions share a common structure among the three economies, they also have idiosyncratic terms as indicated by the general-to-specific element of our estimation procedure.

The labour demand side of the empirical models has the following characteristics. The autoregressive estimates measure employment persistence (due to labour adjustment costs) and are similar in all three economies, ranging from 0.83 to 0.87 . The significant parameter of the labour share conforms with the requirements of a typical labour demand equation, since its wage component has the expected negative effect, and the productivity component can be seen as embodying the positive influence of capital stock and technical progress (Manning, 1993, among others).

Ranking the countries according to the elasticity of employment with respect to the wage-productivity gap, we have that the elasticity is substantially larger in the US than in the two European countries. In particular, the long-run labour share elasticity in the US is almost twice as large as those in the UK: $-2.15,-1.33,-1.12$. Another feature that differentiates labour demand conditions in the US from those in Europe is that, in addition to the wage effect via the labour share, wages have a further direct negative impact on employment. This means that the wage elasticity of labour demand in the US is more than double than that in the UK and Sweden. Furthermore, the influence of the monetary conditions on employment is captured through real balances in the US, and real interest rates in the UK and Sweden. Finally, while there is no demand-side influence in the US, our estimations identify private consumption in the UK and competitiveness in Sweden as relevant employment determinants.

\footnotetext{
${ }^{14}$ The 3SLS results do not differ substantially from the OLS ones which are available upon request.
} 
Table 3. Labour demand $\left(n_{t}\right)$ - inequality $\left(g i n i_{t}\right)$ systems, 3SLS.

US, 1962-2008

$$
\begin{array}{rlllllll}
c n t & n_{t-1} & l s_{t} & w_{t} & r b_{t} & \Delta r b_{t} & \Delta r b_{t-1} \\
n_{t}= & 2.72 & 0.87 & -0.28 & -0.17 & 0.12 & -0.19 & 0.18 \\
{[0.011]} & {[0.000]} & {[0.032]} & {[0.014]} & {[0.010]} & {[0.001]} & {[0.005]} \\
H_{0}: \hat{c}(w)=-\hat{c}(p r): \text { Wald test }\left[\chi^{2}(1)\right]=6.29 ; & \text { S.E. of regression }=0.010
\end{array}
$$$$
\text { cnt } \quad \text { gini }_{t-1} \quad l s_{t-1} \quad f p_{t-1} \quad \tau_{t}^{d} \quad \text { comp }_{t-1}
$$$$
\text { gini }_{t}=\begin{array}{cccccc}
1.54 & 0.78 & -0.40 & 0.07 & -0.60 & 0.02 \\
{[0.003]} & {[0.000]} & {[0.003]} & {[0.118]} & {[0.015]} & {[0.040]}
\end{array}
$$$$
H_{0}: \hat{c}(w)=-\hat{c}(p r): \text { Wald test }\left[\chi^{2}(1)\right]=[0.18 ; \quad \text { S.E. of regression }=0.014
$$

Instruments: cnt, $n_{t-1}, g i n i_{t-1}, l s_{t-1}, l s_{t-2}, w_{t-1}, r b_{t}, r b_{t-1}, r b_{t-2}, \tau_{t}^{d}, \tau_{t-1}^{d}, f p_{t-1}, c o m p_{t-1}$.

UK, 1965-2008

$$
\begin{array}{rlllllll} 
& c n t & n_{t-1} & \Delta n_{t-1} & l s_{t} & \Delta p r_{t-1} & r_{t} & c_{t} \\
n_{t}= & 3.59 & 0.83 & 0.55 & -0.19 & 0.28 & -0.12 & 0.28 \\
{[0.000]} & {[0.000]} & {[0.000]} & {[0.007]} & {[0.002]} & {[0.020]} & {[0.000]}
\end{array}
$$

cnt $\quad g_{i n i} t_{t-1} \quad \Delta g i n i_{t-2} \quad \Delta g i n i_{t-3} \quad l s_{t} \quad \Delta l s_{t-1} \quad w_{t} \quad g s_{t-1} \quad \tau_{t-1}^{i}$

$$
\text { gini }_{t}=\begin{array}{ccccccccc}
0.51 & 0.70 & 0.20 & 0.46 & -0.51 & 0.65 & 0.07 & 0.82 & 1.69 \\
{[0.576]} & {[0.000]} & {[0.007]} & {[0.000]} & {[0.004]} & {[0.001]} & {[0.003]} & {[0.000]} & {[0.000]}
\end{array}
$$

$H_{0}: \hat{c}(w)=-\hat{c}(p r):$ Wald test $\left[\chi^{2}(1)\right]=9.83 ; \quad$ S.E. of regression $=0.014$

Instruments: cnt, $n_{t-1}, n_{t-2}, g i n i_{t-1}, g i n i_{t-2}, g i n i_{t-3}, g i n i_{t-4}, p r_{t-1}, p r_{t-2}, r_{t}, c_{t}, l s_{t-1}, l s_{t-2}, \tau_{t}^{i}, g s_{t-1}$.

\section{Sweden, 1978-2008}

$$
\begin{aligned}
& \text { cnt } \quad n_{t-1} \quad \Delta n_{t-1} \quad l s_{t} \quad r_{t} \quad \Delta r_{t-1} \quad \operatorname{comp}_{t} \\
& n_{t}=\begin{array}{ccccccc}
3.18 & 0.85 & 0.63 & -0.20 & -0.35 & -0.31 & 0.06 \\
{[0.000]} & {[0.000]} & {[0.000]} & {[0.001]} & {[0.002]} & {[0.000]} & {[0.002]}
\end{array}
\end{aligned}
$$

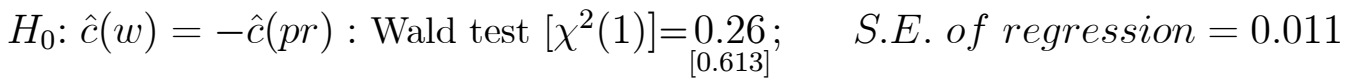

$$
\begin{array}{cccccccccc} 
& c n t & \text { gini }_{t-1} & l s_{t} & \Delta l s_{t} & \Delta w_{t} & n s_{t-1} & u d_{t} & \text { comp }_{t-1} & d^{00} \\
\text { gini }_{t}= & 3.88 & 0.32 & -0.78 & -1.57 & 2.74 & 0.17 & -0.02 & -0.35 & 0.11 \\
{[0.008]} & {[0.062]} & {[0.019]} & {[0.059]} & {[0.013]} & {[0.253]} & {[0.000]} & {[0.014]} & {[0.006]}
\end{array}
$$

$H_{0}: \hat{c}(w)=-\hat{c}(p r):$ Wald test $\left[\chi^{2}(1)\right]=\underset{[0.292]}{1.11} ; \quad$ S.E. of regression $=0.040$

Instruments: $\mathrm{cnt}, n_{t-1}, n_{t-2}, \mathrm{gini}_{t-1}, l s_{t-1}, r_{t}, r_{t-1}, r_{t-2}, \mathrm{comp}_{t}, \mathrm{comp}_{t-1}, w_{t-1}, w_{t-2}, n s_{t}, \mathrm{~d}^{00}$

Notes: $\Delta$ denotes the difference operator; p-values in brackets; $\hat{c}(w)$ and $\hat{c}(p r)$ are the estimated coefficients on real wages and labour productivity. 
The income inequality side of the empirical models has the following features. The wage-productivity gap is a significant determinant of inequality in all three economies. It is interesting to observe that the Gini equations differ substantially in their degree of inertia and persistence in both the Anglo-Saxon countries is quite high (0.78 in the US, 0.70 in the UK) compared to a value of 0.32 in Sweden, the country with the lowest level of income inequality. As a result, the long-run elasticity of the Gini ratio with respect to the labour share is higher in the Anglo-Saxon countries than in Sweden: a one percent fall in the labour share increases inequality by $1.82 \%$ in the US, $1.7 \%$ in the UK, and $1.15 \%$ in Sweden.

Another feature common in the Gini regressions is the upward pressure of the profits of financial corporations on income inequality. Note, however, that although the $f p$ and $g s$ variables are significant at conventional levels in the US and UK, the financial sector variable $n s$ is significant at the $25 \%$ level in Sweden (though we believe this is probably due to the lack of data availability prior to 1993). Finally, the income inequality estimations include some idiosyncratic control variables. From the group of standard institutional variables, direct taxes $\left(\tau^{d}\right)$ are significant in the US (with the expected negative sign), indirect taxes $\left(\tau^{i}\right)$ in the UK (with the expected positive sign), and union density $(u d)$ in Sweden (with the expected negative sign). From the group of foreign-market related variables, competitiveness (comp) worsens inequality in the US (a big economy with a large current account deficit) and reduces inequality in Sweden (a small economy with a current account surplus).

\section{Dynamic Contributions}

In the previous section we assessed the statistical significance of the labour share factor in the labour demand and Gini coefficient equation system. Here we examine its economic significance by measuring how it contributed to employment and income inequality over specific periods in our sample. We first present the conceptual underpinnings of the 'contributions' measure and then evaluate our simulation results.

\subsection{Conceptual Underpinnings}

One of the salient features of our dynamic modelling approach is that we regard a change in an exogenous variable at a point in time as an impulse, i.e. a one-off "shock" to the dependent variable. Defining the shock as a change in an exogenous variable, rather than as a change in the residuals of a behavioural equation, ${ }^{15}$ has a clear advantage: it gives

\footnotetext{
${ }^{15}$ Blanchard (2009, p. 220) correctly points out that "The use of "shocks" is fraught with philosophical, but also with practical, difficulties: Technological shocks, animal spirits, changes in perceived uncertainty, etc. all have deeper causes, which themselves have even deeper causes, and so on."
} 
rise to (dynamic) contributions, a measure that shows how the endogenous variable of a dynamic equation responds to the actual changes in an exogenous variable over a sample interval.

The most pedagogical illustration of the concept of dynamic contributions can be given in the context of a simple $\operatorname{AR}(1)$ model:

$$
y_{t}=\alpha y_{t-1}+\beta(1-\alpha) x_{t}, \text { where }|\alpha|<1 \text {. }
$$

The impulse response function (IRF) of the stochastic process (5) to a one-off unit change in the exogenous variable $x_{t}$ is

$$
\mathrm{IRF}_{t}: \begin{array}{|c|c|c|c|c|c|c|}
\hline \text { time } & t & t+1 & t+2 & \ldots & t+10 & \ldots \\
\hline \text { responses } & \beta(1-\alpha) & \beta(1-\alpha) \alpha & \beta(1-\alpha) \alpha^{2} & \ldots & \beta(1-\alpha) \alpha^{10} & \ldots \\
\hline
\end{array}
$$

Note that a one-time unit shock will have an immediate unit $\times \beta(1-\alpha)$ impact on the endogenous variable, while the future effects of the shock decline in a geometric fashion. We can summarise the sensitivity of $y$ with respect to variable $x$ as:

$$
\begin{gathered}
\text { long-run sensitivity }=\begin{array}{c}
\text { short-run sensitivity }+ \text { persistence } \\
\beta
\end{array} \quad \beta(1-\alpha) \\
\beta \alpha
\end{gathered}
$$

where persistence is defined as the sum of future responses (i.e. the responses in the aftermath of the shock), short-run sensitivity refers to the contemporaneous response, and the long-run sensitivity is given by the sum of all responses.

On the basis of the above analysis, we measure the contributions of the exogenous variable $x$ to the evolution of the dependent variable $y$ over a specific time interval of $T$ periods, say $t+1$ to $t+T$, by sequentially adding up the IRFs of the respective shocks during the specific period. We define the shock at each point in time as the change in the $x$ series from period $t$ to $t+i: \nabla_{i} x_{t+i}=x_{t+i}-x_{t}$, where $\nabla_{i}$ denotes the backward difference of $i$ periods, $i=1,2, \ldots, T$. The IRFs of the dependent variable to these shocks are

$$
\left[\begin{array}{ccccc} 
& t+1 & t+2 & \ldots & t+T \\
\mathrm{IRF}_{1}: & R_{11} & R_{12} & \ldots & R_{1 T} \\
\mathrm{IRF}_{2}: & - & R_{22} & \ldots & R_{2 T} \\
\ldots & - & - & \ldots & \ldots \\
\mathrm{IRF}_{T}: & - & - & \ldots & R_{T T}
\end{array}\right]
$$

where $\operatorname{IRF}_{i}$ denotes the response function of the endogenous variable to the $i$ th shock, and $R_{i j}$ is the response to shock $i$ in time $t+j$. Note that the diagonal elements in matrix (8) denote the respective contemporaneous $y$-responses to the $i$ th shock, whereas the elements above the diagonal denote the $y$-responses in period $t+j$ to the shocks which 
occurred in past periods. Therefore, the $(t+j)$-period contribution can be obtained as the sum of all responses in this period.

In other words, the contributions of the exogenous variable $x$ to the trajectory of the endogenous variable for the given interval are given by the following time series:

$$
\begin{array}{ccccc}
t+1 & t+2 & t+3 & \ldots & t+T \\
R_{11}, & \sum_{i=1}^{2} R_{i 2}, & \sum_{i=1}^{3} R_{i 3}, & \ldots & \sum_{i=1}^{T} R_{i T}
\end{array}
$$

which is equivalent to the disparity between the actual (fitted) and simulated values at period $t+i, i=1, \ldots, T$.

In the context of a model where the labour share is the driving force of employment and income inequality, we illuminate the analytics of the contributions measure through an autoregressive $\mathrm{AR}(1)$ process. (The simple static case is analysed in the Appendix.)

\section{Contributions: AR1 Case}

Let $y$ (say, employment) depend on $x$ (say, the labour share) and suppose that $y$ follows the $\operatorname{AR}(1)$ stochastic process (5), i.e. $y_{t}=\alpha y_{t-1}+\beta(1-\alpha) x_{t}$, where (in the light of our results in Section 4) $\beta<0$. We fix $x_{t}=x_{0}$, for $t=1, \ldots, T$. Thus, we can express the shock series as

$$
\operatorname{shock}_{t} \equiv \nabla_{t} x_{t}=x_{t}-x_{0}
$$

and the size over the specific period is

$$
\text { size }=\nabla_{T} x_{T}=x_{T}-x_{0} .
$$

In this case the responses of $y$ to the changes in $x$ (shocks) are

$$
\left[\begin{array}{ccccc} 
& t=1 & t=2 & \ldots & t=T \\
\operatorname{IRF}_{1} & \beta(1-\alpha)\left(x_{1}-x_{0}\right) & \beta(1-\alpha) \alpha \nabla_{1} x_{1} & \ldots & \beta(1-\alpha) \alpha^{T-1} \nabla_{1} x_{1} \\
\mathrm{IRF}_{2} & - & -\beta(1-\alpha) \nabla_{2} x_{2} & \ldots & \beta(1-\alpha) \alpha^{T-2} \nabla_{2} x_{2} \\
\ldots & - & - & \ldots & \ldots \\
\mathrm{IRF}_{T} & - & - & \ldots & \beta(1-\alpha)\left(x_{T}-x_{0}\right)
\end{array}\right],
$$

and the contribution of $x$ to the evolution of $y$ over the $[1, T]$ interval is measured by the sum of all responses in the last column of the above matrix (see also equation (9)):

$\beta(1-\alpha) \sum_{t=1}^{T-1} \alpha^{T-t} \nabla_{t} x_{t}+\beta(1-\alpha)\left(x_{T}-x_{0}\right)=($ frictional impact on $y)+\beta(1-\alpha)($ size $)$. 
In turn, unlike the white noise case, the sensitivity of $y$ to the change in $x$ over the whole period depends on the size of the shock:

$$
\frac{(\text { frictional impact on } y)+\beta(1-\alpha)(\text { size })}{\text { size }}=\frac{\beta(1-\alpha) \sum_{t=1}^{T} \alpha^{T-t} \nabla_{t} x_{t}}{\left(x_{T}-x_{0}\right)} \text {. }
$$

Note that the frictional impact is nullified in the long run, since the matrix (12) becomes redundant. A long-run analysis of the $\mathrm{AR}(1)$ model shows that all temporary shocks dissipate with time, while a permanent shock (say, a decrease in the labour share) causes employment to increase by $\beta$ times the size of the permanent shock. However, in a finite time period the sensitivity (elasticity) of $y$ with respect to $x$ depends on the size of the shock. In short,

- if $\alpha=0$ then the elasticity (sensitivity) of employment $(y)$ with respect to the labour share $(x)$ is zero;

- if $\alpha>0$ then the elasticity of $y$ with respect to $x$ is a weighted average of each period's shocks $\left(\nabla_{t} x_{t}\right)$ as a percentage of the size of the shock, i.e. the overall change in $x$ in the given period $\left(x_{T}-x_{0}\right)$.

Along the same lines, if we let $z$ (the Gini coefficient) to follow an $\operatorname{AR}(1)$ process

$$
z_{t}=\phi z_{t-1}+\gamma(1-\phi) x_{t},|\alpha|<1
$$

the contributions are

$\gamma(1-\phi) \sum_{t=1}^{T-1} \phi^{T-t} \nabla_{t} x_{t}+\gamma(1-\phi)\left(x_{T}-x_{0}\right)=($ frictional impact on $z)+\gamma(1-\phi)($ size $)$,

and the elasticity of $z$ with respect to $x$ is

$$
\frac{(\text { frictional impact on } z)+\gamma(1-\phi)(\text { size })}{\text { size }}=\frac{\gamma(1-\phi) \sum_{t=1}^{T} \phi^{T-t} \nabla_{t} x_{t}}{\left(x_{T}-x_{0}\right)} .
$$

A similar reasoning applies to the above equation as for the $y$ sensitivity in equation (14).

Finally, the inequality cost for the employment boost due to the fall in the labour share depends on the size of the shock, i.e the change in $x$ from period $t=0$ to $t=T$ :

$$
\frac{d z}{d y}=\frac{\gamma(1-\phi) \sum_{i=1}^{T-1} \phi^{T-t} \nabla_{t} x_{t}+\gamma(1-\phi)\left(x_{T}-x_{0}\right)}{\beta(1-\alpha) \sum_{i=1}^{T-1} \alpha^{T-t} \nabla_{t} x_{t}+\beta(1-\alpha)\left(x_{T}-x_{0}\right)}=\frac{\gamma(1-\phi) \sum_{i=1}^{T} \phi^{T-i} x_{i}}{\beta(1-\alpha) \sum_{i=1}^{T} \alpha^{T-i} x_{i}}
$$


Note that in a dynamic model the sensitivity ratio of inequality and employment $(d z / d y)$ does not depend on the size of the shock when $\phi=\alpha$. Naturally,

- the smaller the difference between (i) the autoregressive parameters $(\phi, \alpha)$ and (ii) the labour share elasticities $(\gamma, \beta)$ of the two equations, the smaller the influence of the size of the shock on the sensitivity ratio.

\subsection{Evaluating the Labour Share Contributions}

We evaluate the contributions of the labour share to the inequality and employment trajectories of each country by applying the technique described in the previous section. To this end we carry out counterfactual simulations by fixing the labour share, in the system estimations of Table 3 , at its value at the start of a particular time interval. It is important to point out that fixing the labour share at a specific value over a given time period, we effectively "lock in" the distance between wages and productivity by adjusting accordingly the wage component, while allowing the productivity series (and thus employment) to move "freely" in the equation system. Therefore, the contribution of the labour share to the employment trajectory is measured without the risk of being contaminated by spillovers.

In the US, the labour share fell from $66.4 \%$ in 1992 to $64 \%$ in 2000 and to $63 \%$ by 2008 (see Figure 5b). We measure the effect of these wage gaps on the Gini coefficient and employment time paths over the 1992-00 and 2000-08 periods by keeping the labour share constant at its 1992 and 2000 values, respectively, and simulating the estimated system. The solid and dotted lines in Figures 5c-f plot the actual and simulated trajectories of the Gini coefficient and employment; the disparity between the actual and simulated series measures the dynamic contributions of the wage gap to the variable under examination.

In particular, Figure 5c deals with the question "Had the labour share remained at $66.4 \%$, i.e. at its 1992 value, what would have been the value of the Gini coefficient in 2000?" The distance between the solid and dotted lines in Figure 5b measures the cumulation of "shocks" experienced in each year; by 2000 the magnitude of the labour share shocks was -2.4 percentage points. In turn, the distance between the solid and dotted lines in Figure 5c measures the dynamic contributions of the labour share to the Gini coefficient time path. We thus find an elasticity of the Gini coefficient with respect to the labour share equal to $-2.17\left(\frac{\Delta g i n i}{\Delta l s}=\frac{-.915+.837}{4.196-4.16}\right)$, i.e. a one percent fall in the labour share worsened inequality by $2.17 \%$ in the US over the $1992-00$ period. Or, alternatively, for each percentage point fall in the labour share the Gini coefficient increased by 1.33 percentage points. ${ }^{16}$

\footnotetext{
${ }^{16}$ That is, $\frac{\Delta \text { Gini }}{\Delta \mathrm{LS}}=\frac{0.401-0.433}{0.664-0.64}=1.33$, where Gini and LS are the level values of the respective variables.
} 
Figure 5. Dynamic contributions in the US.

a. Actual and fitted values.

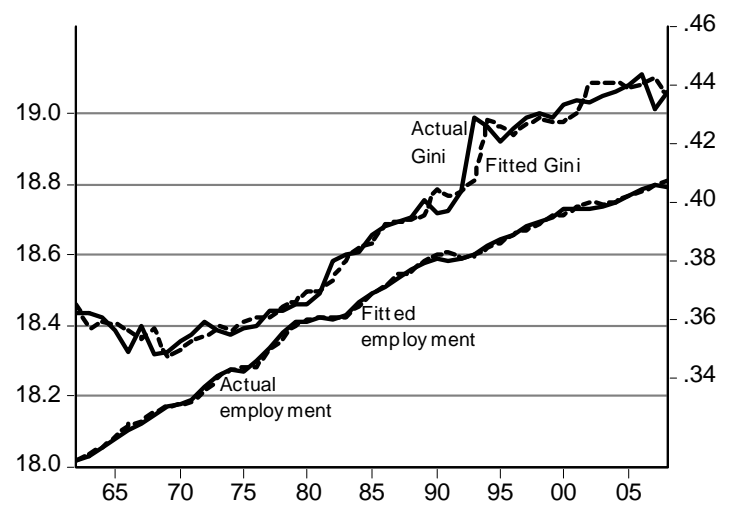

c. Gini, 1992-2000.

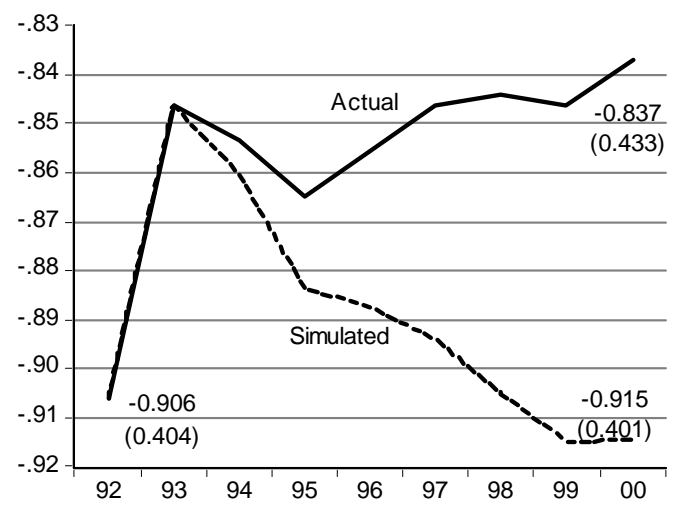

e. Gini, 2000-2008.

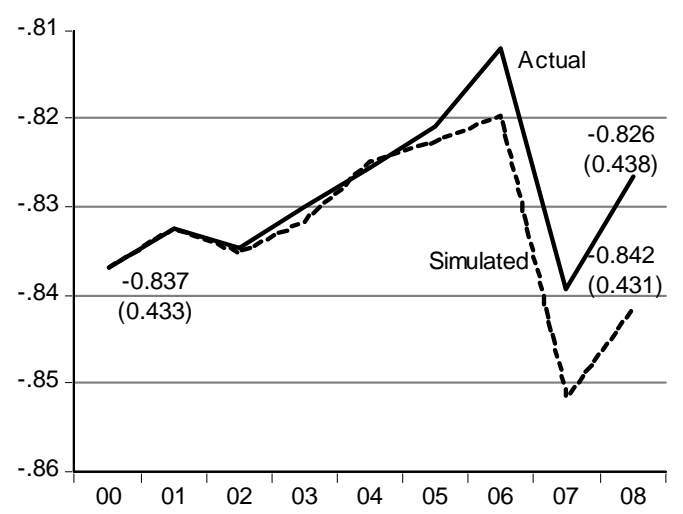

b. Labour share.

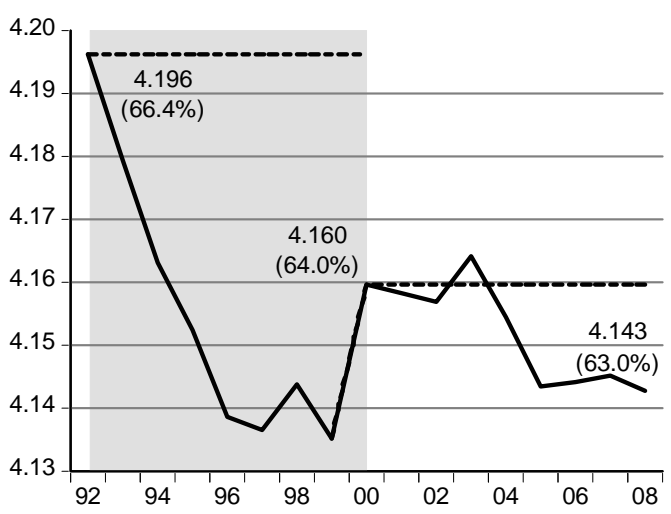

d. Em ploym ent, 1992-2000.

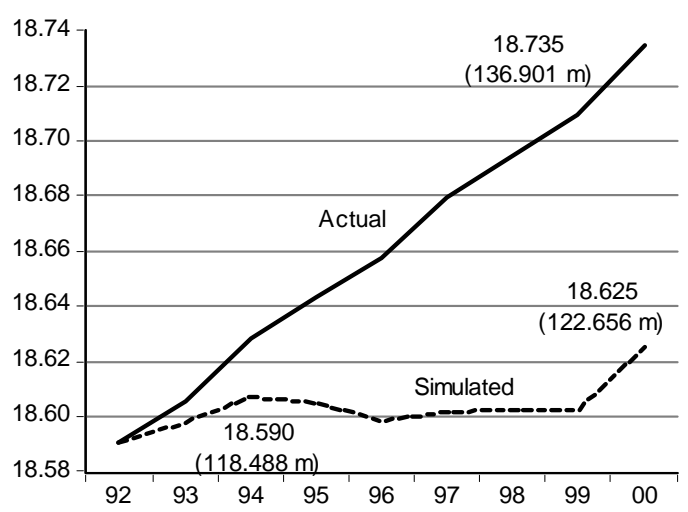

f. Em ployme nt, 2000-2008.

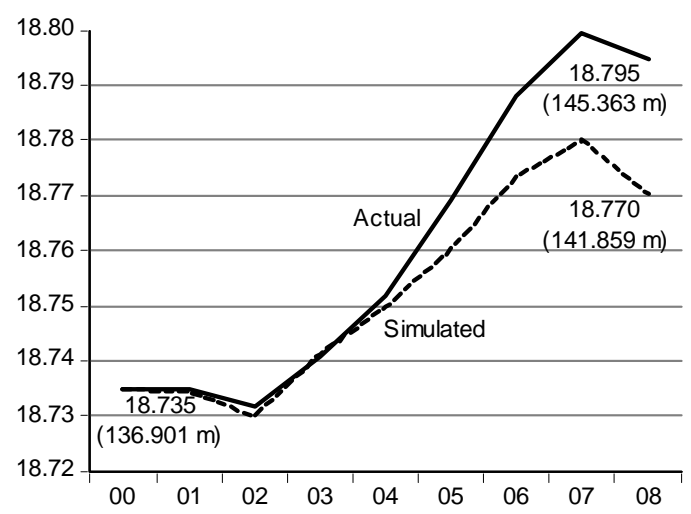

Nevertheless, as shown in Figure 5d, the inequality increase was accompanied by a rise in employment. Note that an extra 14.245 million (136.901-122.656) jobs were created in response to the widening wage-productivity gap, which implies that the elasticity of employment with respect to the labour share is $-3.06\left(\frac{\Delta n}{\Delta l s}=\frac{18.625-18.735}{4.196-4.16}\right)$. The overall sensitivity (elasticity) ratio is $\frac{\Delta g i n i}{\Delta n}=0.71$, i.e. a one percent increase in employment is created at the expense of $0.71 \%$ deterioration of inequality.

In a similar fashion, the contributions of the labour share to the Gini coefficient and employment are calculated for the US during the 2000s and are portrayed in Figures 5e-f, while Figures 6 and 7 plot the labour share contributions in the UK and Sweden. Figures 
6a and 7a depict the evolution of the labour share in the UK and Sweden during the periods under examination. In the UK the labour share fell from $74.5 \%$ in 1990 to $69 \%$ in 1997, then increased to $72.3 \%$ by 2001 and finally fell to $69.7 \%$ by 2008 . In Sweden the labour share dropped by 8.5 percentage points (from $74.2 \%$ to $62.7 \%$ ) during the recession of the first half of the nineties, increased to $69.4 \%$ by 2001 , and then fell slightly to $68.1 \%$ by 2008. The labour share elasticities $\left(\frac{\Delta g i n i}{\Delta l s}, \frac{\Delta n}{\Delta l s}\right)$ and the implied inequality/employment sensitivity ratio $\left(\frac{\Delta \text { gini }}{\Delta n}\right)$ for the three countries during the respective simulation periods are summarised in Table 6 .

Table 6. Labour share elasticities of inequality and employment.

\begin{tabular}{|c|c|c|c|c|c|c|c|c|}
\hline & \multicolumn{2}{|c|}{ US } & \multicolumn{3}{|c|}{ UK } & \multicolumn{3}{|c|}{ Sweden } \\
\hline & $92-00$ & $00-08$ & $90-97$ & $97-01$ & 01-08 & $90-95$ & $95-01$ & 01-08 \\
\hline$\%$ & & & & & & & & \\
\hline$\Delta g i n i / \Delta l s$ & -2.17 & -0.94 & -0.55 & -0.51 & -1.08 & -0.54 & -0.67 & -2.55 \\
\hline$\Delta n / \Delta l s$ & -3.06 & -1.47 & -0.73 & -0.57 & -0.83 & -0.66 & -0.96 & -2.35 \\
\hline$\Delta g i n i / \Delta n$ & 0.71 & 0.64 & 0.75 & 0.89 & 1.30 & 0.82 & 0.69 & 1.09 \\
\hline
\end{tabular}

The following points are worth noting. First, although inequality and employment in the US were highly elastic with respect to the falling labour share in the nineties, almost four times more elastic than those in the European countries, their sensitivity ratio was lower than that in the UK and Sweden: the cost of a one percent boost in employment in the US was a $0.71 \%$ increase in inequality - the European cost was $0.75 \%$ in the UK and $82 \%$ in Sweden.

Second, in the UK a one percent increase in employment has been achieved at the expense of higher percentage increases in inequality throughout the years. This was due to the approximate doubling of the labour share elasticity of inequality $\left(\frac{\Delta g i n i}{\Delta l s}\right)$ from the 1990-97 period to the 2001-08 one, implying that the same percentage fall in the labour share in the 1990s led to twice as much the rise in inequality in the 2000s. Over the 2001-08 period the sensitivity ratio was the highest in the sample with a $1 \%$ employment increase being obtained at the cost of $1.3 \%$ deterioration in inequality. In contrast, the US displayed a sensitivity ratio of 0.64 in the noughties, reflecting the lowest inequality cost in the sample associated with a $1 \%$ rise in employment due to the falling labour share.

Third, similar to the US in the nineties, Sweden experienced the highest inequality and employment elasticities with respect to the labour share during the noughties. The main difference, however, is that Sweden exhibits an elastic sensitivity ratio of 1.09 in the 2000s compared with the lower $\frac{\Delta g i n i}{\Delta n}=0.71$ in the US during the 1990s. 
Figure 6. Dynamic contributions in the UK.

a. Actual and fitted values.

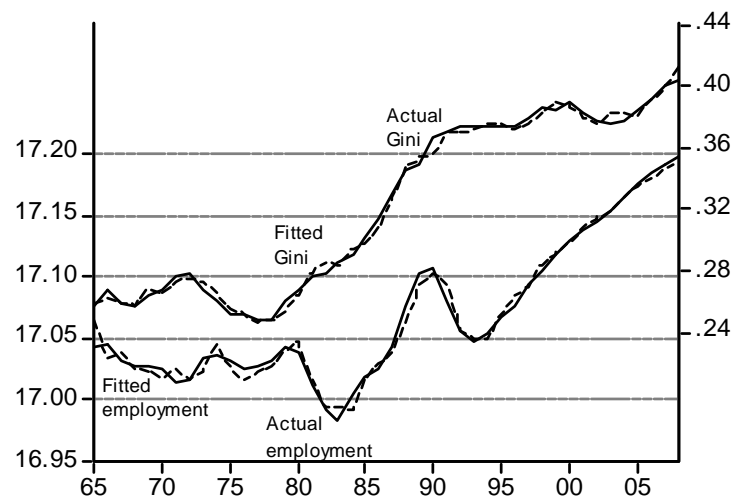

c. Gini, 1990-1997.

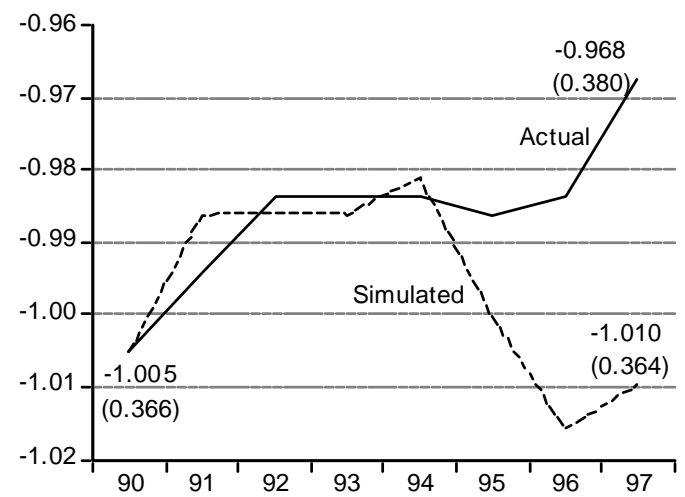

e. Gini, 1997-2001.

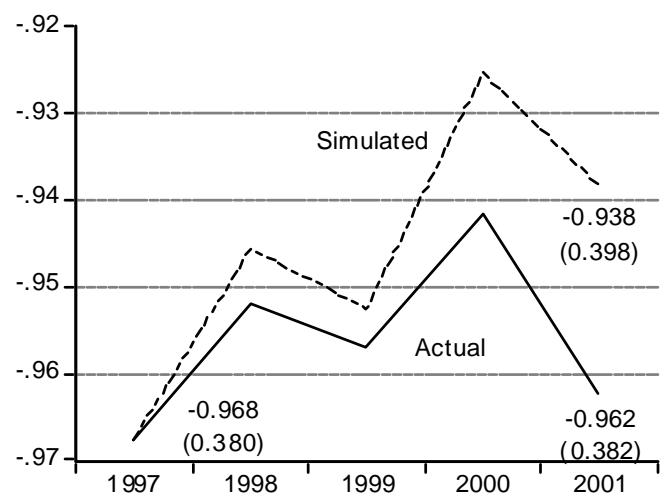

g. Gini, 2001-2008.

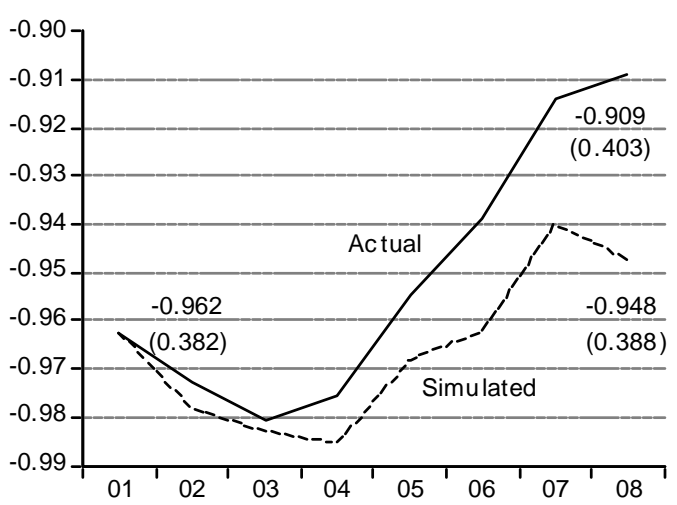

b. Labour share

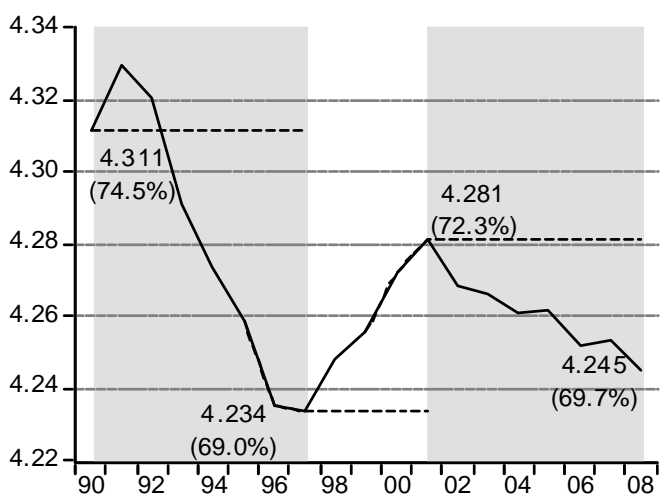

d. Employment, 1990-1997.

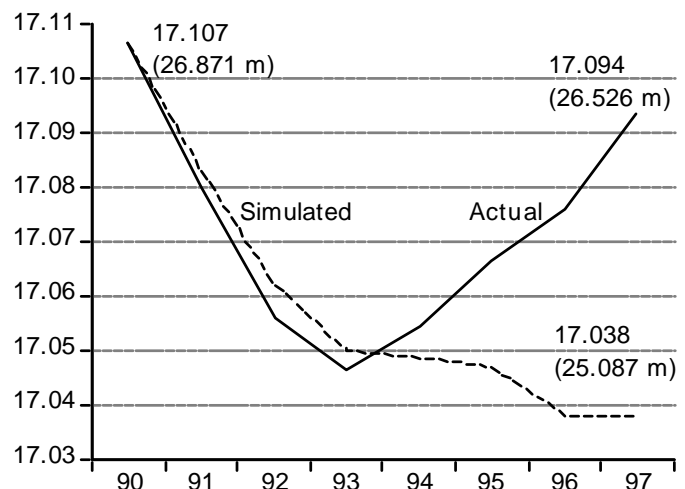

f. Employment, 1997-2001.

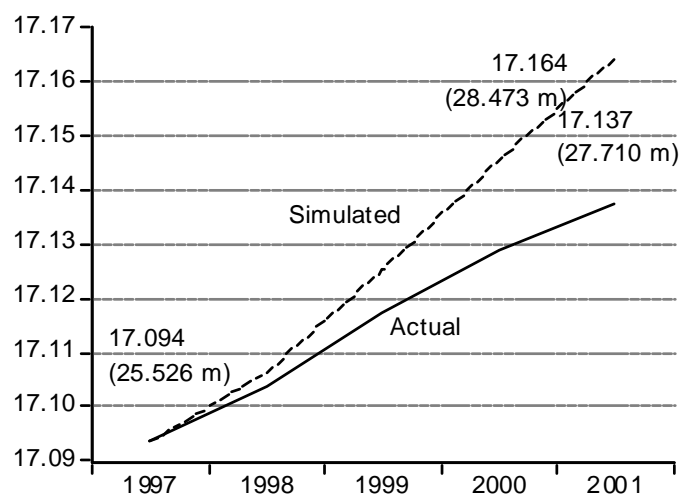

h. Employment, 2001-2008.

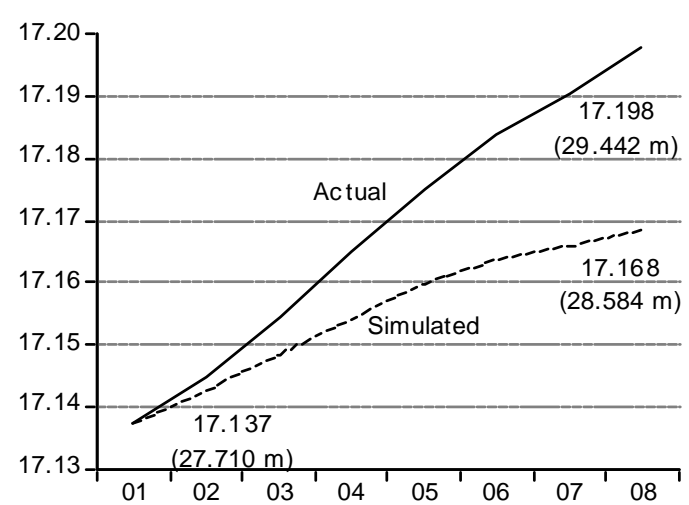


Figure 7. Dynamic contributions in Sweden.

a. Actual and fitted values.

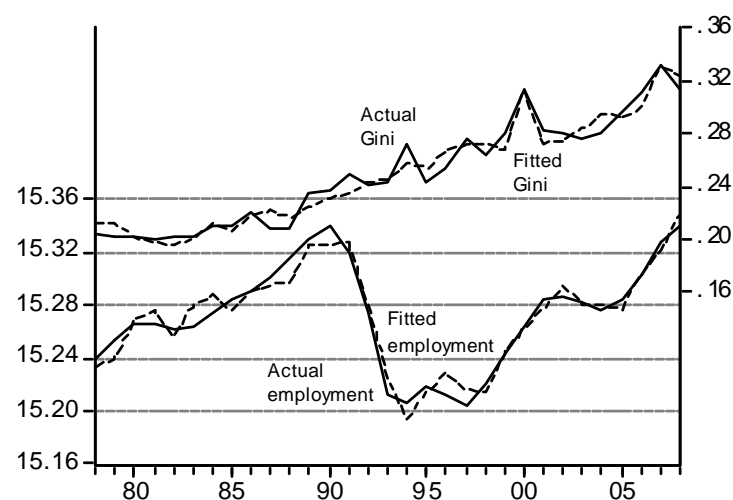

c. Gini, 1990-1995

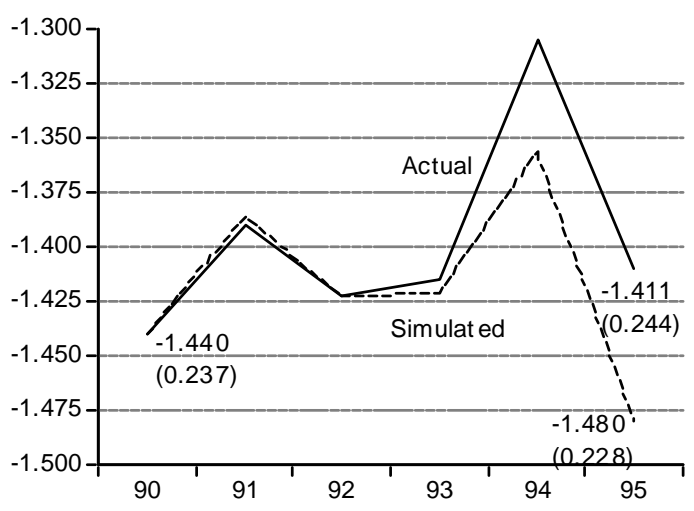

e. Gini, 1995-2001

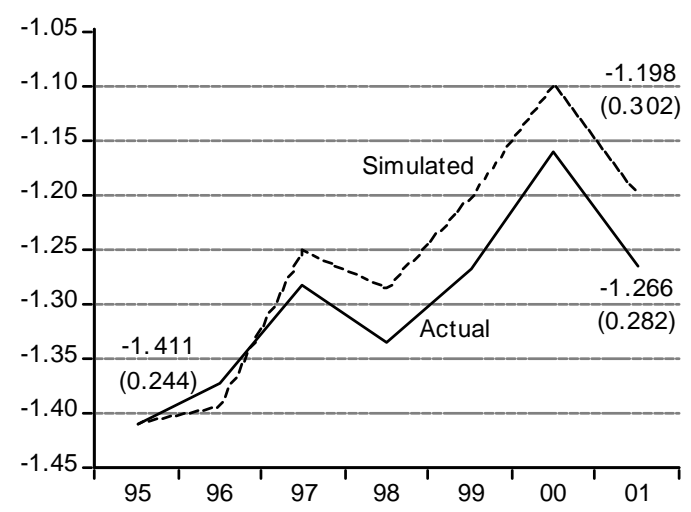

g. Gini, 2001-2008.

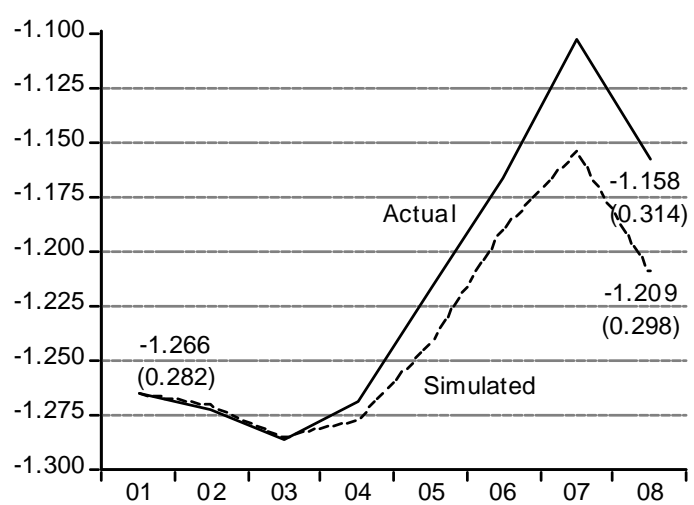

b. Labour share

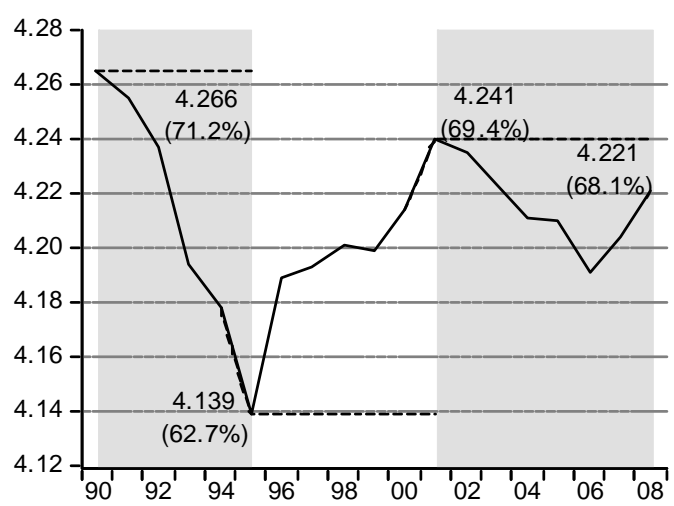

d. Employment, 1990-1995.

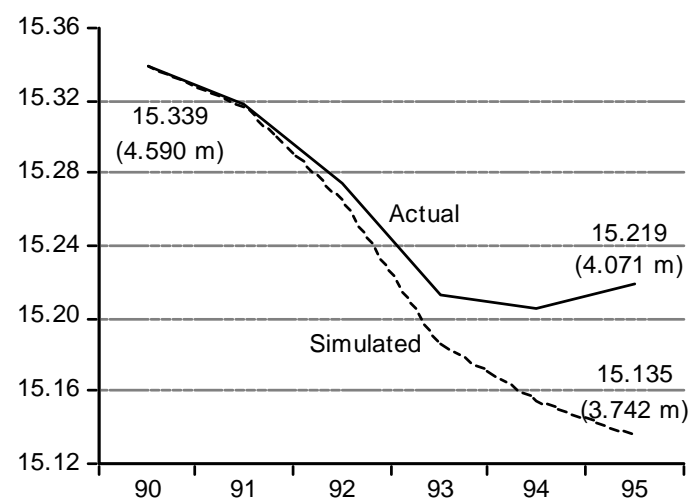

f. Employment, 1995-2001.

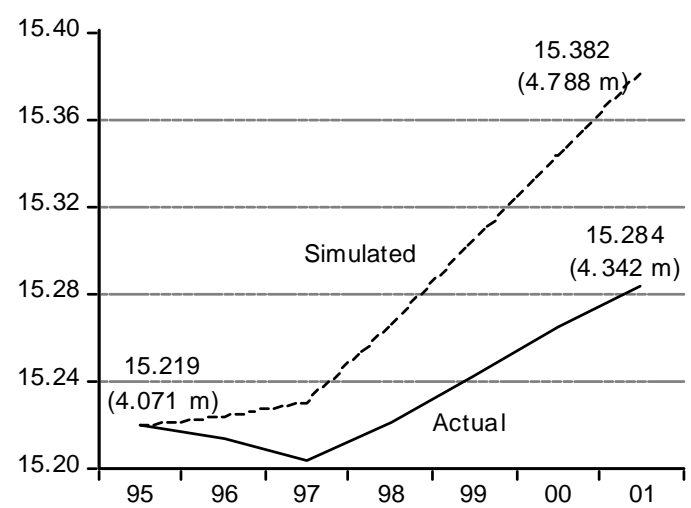

h. Employment, 2001-2008.

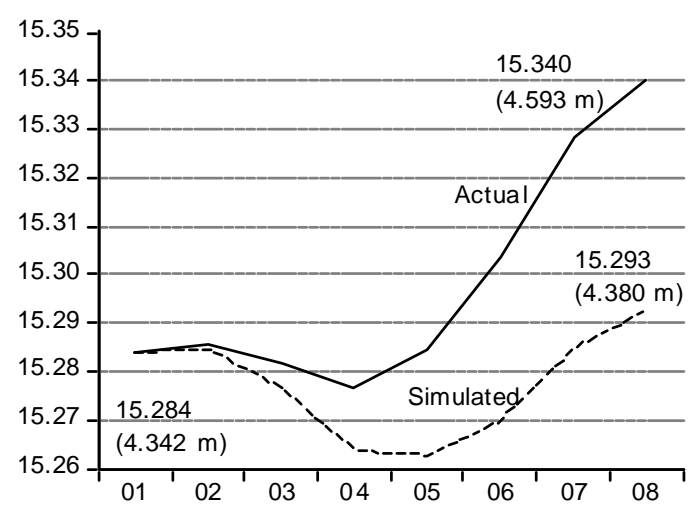


Finally, observe, that out of the eight time intervals we examine, there are only two periods during which the labour share is increasing: 1997-2001, the first labour term in the post-Thatcher UK, and the 1995-2001 recovery period in Sweden. In the case of rising labour shares, the higher the sensitivity ratio $\frac{\Delta g i n i}{\Delta n}$, the higher the economic benefits. According to Table 6 , a $1 \%$ decrease in employment was accompanied by $0.89 \%$ less inequality in the UK and $0.69 \%$ less inequality in Sweden. So in the second half of the nineties the UK performed better than Sweden, since it achieved a larger reduction in inequality for the same employment loss.

\section{Conclusions}

In this paper we examined how the falling labour share (or, equivalently, the widening wage-productivity gap) influenced the employment trajectory and solicited the increasing inequality in the US, UK and Sweden over the past four decades. Using annual data, we estimated systems of labour demand and Gini coefficient equations with the aim to optimise the fit in each country.

Having validated, in statistical terms, the labour share as a major driving force of inequality and employment, we confirmed the economic significance of our results via counterfactual simulations that measured the contributions of the wage-productivity gap to the evolution of the two series, and evaluated the labour share elasticities of inequality and employment (and the corresponding sensitivity ratios).

According to our findings, as labour shares were falling during the nineties, the inequality-employment sensitivity ratio in the $\underset{90-00}{\mathrm{US}}$ was lower than that in the $\underset{90-97}{\mathrm{UK}}$ and Sweden: a one percent increase in employment was supported at the expense of higher inequality by $0.71 \%$ in the US, $0.75 \%$ in the UK, and $0.82 \%$ in Sweden. In the two simulation periods during which labour shares were rising, i.e. 1997-2001 in the UK and 1995-2001 in Sweden, the UK achieved a larger reduction in inequality than Sweden (0.89\% compared to $0.69 \%$ ) for the same percentage loss in employment. This picture of the two European countries is in striking contrast to that in the noughties. In particular, we found that the inequality-employment sensitivity ratio was much more elastic in the UK and Sweden than in the US in the 2000s. That is, as the labour shares were falling, the cost of one percent boost in employment was an increase in inequality of $0.64 \%$ in the US, $1.30 \%$ in the UK, and $1.09 \%$ in Sweden.

Acknowledging the crucial impact of the labour share on the inequality and employment time paths, the evolution of the wage-productivity gap deserves the attention of policy makers. Although an investigation of which macro-labour factors are driving the labour share was beyond the scope of this paper, we endeavour to address this substantive theme in future work. It should also be worth examining to what extent the various 
income groups benefit/loose from falling labour shares.

The empirical evidence that the falling labour share leads to higher Gini coefficients, while supporting employment, suggests that the attention of developed democratic societies is diverted away from the issue of increasing income inequality through "sweetening" its impact. Or, as George Monbiot opined, "Governments ensure that we are thrown enough scraps to keep us quiet, while the ultra-rich get on with the serious business of looting the global economy and crushing attempts to hold them to account." (The Guardian, 'To us, it's an obscure shift of tax law. To the City, it's the heist of the century', 8 Feb 2011.)

Nevertheless, it is vital to bear in mind, especially in the precarious post-2008 era, that in an environment of increasing inequality, countries with high or rising unemployment rates may have to confront tense socioeconomic conditions.

\section{Appendix}

\section{Contributions: Static Case}

Let $y$ (employment) depend on $x$ (labour share):

$$
y_{t}=\beta x_{t}
$$

where (as shown in Section 4) $\beta<0$. Fixing $x_{t}=x_{0}$ for $t=1, \ldots, T$, the shock series and the size over the specific period are given by equations (10)-(11):

$$
\text { shock } k_{t} \equiv \nabla_{t} x_{t}=x_{t}-x_{0}, \quad \text { size }=\nabla_{T} x_{T}=x_{T}-x_{0} .
$$

The responses in matrix (8) are

$$
\left[\begin{array}{cccccc} 
& t=1 & t=2 & t=3 & \ldots & t=T \\
\mathrm{IRF}_{1}: & \beta\left(x_{1}-x_{0}\right) & 0 & 0 & \ldots & 0 \\
\mathrm{IRF}_{2}: & - & \beta\left(x_{2}-x_{0}\right) & 0 & \ldots & 0 \\
\ldots & - & - & \beta\left(x_{3}-x_{0}\right) & \ldots & 0 \\
& - & - & - & \ldots & \ldots \\
\mathrm{IRF}_{T}: & - & - & - & \ldots & \beta\left(x_{T}-x_{0}\right)
\end{array}\right] .
$$

Over the specific period, we measure the contribution of the $x$ shocks to $y$ as the disparity between its actual (fitted) and simulated values at period $T$ :

$$
y_{T}-\beta x_{0}=\beta x_{T}-\beta x_{0}=\beta\left(x_{T}-x_{0}\right)=\beta(\text { size }) .
$$

Alternatively, the contributions at the end of the period are obtained by applying eq. (9) to matrix (20), i.e. adding up all responses in its last column:

$$
\sum_{i=1}^{T} R_{i T}=0+0+0 \ldots+\beta\left(x_{T}-x_{0}\right) .
$$


We then define the sensitivity of $y$ to the change in $x$ over the whole period as:

$$
\frac{y_{T}-\beta x_{0}}{\text { size }}=\frac{\beta\left(x_{T}-x_{0}\right)}{\text { size }}=\beta \text {. }
$$

Similarly, let us consider that $z$ (the Gini coefficient) also depends on $x$ (the labour share):

$$
z_{t}=\gamma x_{t}
$$

Along the above lines, we measure the contribution of $x$ to $z$ and the sensitivity of $z$ with respect to $x$ as:

$$
\begin{gathered}
z_{T}-\gamma x_{0}=\gamma x_{T}-\gamma x_{0}=\gamma\left(x_{T}-x_{0}\right)=\gamma(\text { size }) \\
\frac{z_{T}-\gamma x_{0}}{\text { size }}=\gamma
\end{gathered}
$$

Therefore, the sensitivity ratio of inequality $(z)$ and employment $(y)$ as a result of the change in the labour share $(x)$ over the specific period is

$$
\frac{d z}{d y}=\frac{\gamma}{\beta}
$$

Note that in the absence of dynamics the sensitivity ratio does not depend on the size of the change in the labour share.

\section{References}

[1] Atkinson, A.B. (1997): "Bringing Income Distribution in from the Cold", The Economic Journal, vol. 107, pp. 297-321.

[2] Atkinson, A.B. (2001): "A Critique on the Transatlantic Consensus on Rising Income Inequality", World Economy, vol. 24, pp. 433-452.

[3] Bental, B. and Demouguin, D. (2010): "Declining labor shares and bargaining power: An institutional explanation", Journal of Macroeconomics, vol. 32, pp. 443-456.

[4] Bentolila, S. and Saint-Paul, G. (2003): "Explaining movements in the labor share", Contributions to Macroeconomics, vol. 3 (1), Article 9.

[5] Björklund, A. (1991): "Unemployment and income distribution: time-series evidence from Sweden", Scandinavian Journal of Economics, vol. 93, 457-4̈65.

[6] Blanchard, O.J. (2006): "European Unemployment", Economic Policy, January, pp. 6-59.

[7] Blancard, O.J. (2009): "The State of Macro", Annual Review of Economics, vol. 1, pp. 209-228.

[8] Blinder, A. and H. Esaki (1978): "Macroeconomic activity and income distribution in the postwar United States", The Review of Economics and Statistics, vol. 60(4), pp. 604-609.

[9] Bourguignon, F. and Morrisson, C. (2002): "Inequality Among World Citizens: 1820-1992", The American Economic Review, vol. 92, pp. 727-744.

[10] Checchi, D. and C. García-Peñalosa (2010): "Labour Market Institutions and the Personal Distribution of Income in the OECD", Economica, vol. 77, pp. 413-450.

[11] Cysne, R.P. (2009): "On the Positive Correlation between Income Inequality and Unemployment", The Review of Economics and Statistics, vol. 91(1), 218-226. 
[12] Ellis, L., and K. Smith (2007): "The Global Upward Trend in the Profit Share", BIS Working Paper No. 231, July, Bank of International Settlements.

[13] Galor, O. (2011): "Inequality, Human Capital Formation and the Process of Development", NBER Working Paper No. 17058.

[14] Galor, O., and O. Moav (2004): "From Physical to Human Capital Accumulation: Inequality and the Process of Development", Review of Economic Studies, vol. 71, pp. 1001-1026.

[15] Guscina, A. (2006): "Effects of Globalization on Labor's Share in National Income", IMF Working Paper 06/294, International Monetary Fund, Washington, DC.

[16] Hatton, T.J. (2007): "Can Productivity Growth Explain the NAIRU? Long-Run Evidence from Britain, 1871-1999", Economica, vol. 74, pp. 475-491.

[17] Hellier, J., and N. Chusseau (2010): "Globalization and the Inequality-Unemployment Tradeoff", Review of International Economics, vol. 18, 1028-1043.

[18] IMF (2007): "The globalization of labor", World Economic Outlook, April, IMF: Washington.

[19] Jäntti, M. and S.P. Jenkins (2010): "The impact of macroeconomic conditions on income inequality", Journal of Economic Inequality, vol. 8, pp. 221-240.

[20] Joyce, R., A. Muriel, D. Phillips, and L. Sibieta (2010): "Poverty and Inequality in the UK: 2010", IFS Commentary No. 116, IFS: London.

[21] Karanassou, M. and H. Sala (2010): "The Wage-Productivity Gap Revisited: Is the Labour Share Neutral to Employment?", IZA Discussion Paper No. 5092, IZA: Bonn.

[22] Krugman, P. (1994): "Past and Prospective Causes of High Unemployment", Economic Review, Federal Reserve Bank of Kansas City, issue Q IV, pp. 23-43.

[23] Llense, F. (2010): "French CEOs' compensations: What is the cost of a mandatory upper limit?", CESifo Economic Studies, vol. 56 (2), pp. 165-191.

[24] Mankiw, N.G.(2010): "Spreading the Wealth Around: Reflections Inspired by Joe the Plumber", NBER Working Paper No. 15846.

[25] Manning, A. (1993): "Wage bargaining and the Phillips curve: the identification and specification of aggregate wage equations", The Economic Journal, vol. 103, pp. 98-118.

[26] Milberg, W. and D. Schöller (2008): "Globalization, Offshoring and Economic Insecurity in Industrialized Countries", Background paper for United Nations Department of Economic and Social Affairs.

[27] Milberg, W., and D. Winkler (2010): "Financialisation and the dynamics of offshoring in the USA", Cambridge Journal of Economics, vol. 34, 275-293.

[28] Metcalf, C.E. (1969): "The size distribution of personal income during the business cycle", American Economic Review, vol. 59 (4), 657-668.

[29] Mocan, H.N. (1999): "Structural unemployment, cyclical unemployment and income inequality", Review of Economics and Statistics, vol. 81 (1), 122-135.

[30] Moriguchi, C. (2010): "Top wage incomes in Japan, 1951-2005", The Journal of the Japanese and International Economies, vol. 32 (1), pp. 492-496.

[31] Nolan, B. (1987): "Cyclical Fluctuations in Factor Shares and the Size Distribution of Income", Review of Income and Wealth, vol. 33, 193-210.

[32] Nolan, B. (1988-89): "Macroeconomic conditions and the size distribution of income: evidence from the United Kingdom", Journal of Post Keynesian Economics, vol. 11(2), 196-221. 
[33] Pesaran, M.H. (1997): "The Role of Economic Theory in Modelling the Long Run", The Economic Journal, vol. 107(440), pp. 178-91.

[34] Pesaran, M.H. and Shin, Y. (1999): "An Autoregressive Distributed-Lag Modelling Approach to Cointegration Analysis" in Econometrics and Economic Theory in the Twentieth Century: The Ragnar Frisch Centennial Symposium, edited by Strom, S., Cambridge University Press, pp. 371-413.

[35] Pesaran, M.H., Y. Shin, and Smith, R.J. (2001): "Bounds testing approaches to the analysis of level relationships", Journal of Applied Econometrics, vol. 16, pp. 289-326.

[36] Piketty, T. and Saez, E. (2006): "The Evolution of Top Incomes: A Historical and International Perspective", The American Economic Review, vol. 96, 200-205.

[37] Schultz, P.T. (1969): "Secular Trends and Cyclical Behavior of Income Distribution in the United States: 1944-1965", NBER, http://www.nber.org/chapters/c4341

[38] Shorrocks, A. (2005): "Inequality values and unequal shares", paper presented at the UNUWIDER Jubilee Conference: WIDER thinking ahead: The future of development economics, 17-18 June 2005, Helsinki, Finland.

[39] Singh, A. (2001): "Income Inequality in Advanced Economies: A Critical Examination of the Trade and Technology Theories and an Alternative Perspective", ESRC Centre for Business Research, Working Paper 219.

[40] Stockhammer, E. (2004): "Financialisation and the Slowdown of Accumulation", Cambridge Journal of Economics, vol. 28, 719-741.

[41] Thurow, L.C. (1970): "Analyzing the American income distribution", American Economic Review, vol. 60(2), 261-269.

[42] Tobin, J. (1972): "Inflation and Unemployment", The American Economic Review, vol. 62(1), pp. 1-18.

[43] Wolff, E.N. and Zacharias, A. (2006): "Wealth and Income Inequality: Who's at the Top of the Economic Ladder?", The Levy Economics Institute of Bard College, LIMEW Report, December 2006. 